\title{
4. Too Old to Work, or Too Young to Retire? The Pervasiveness of Age Norms in Western European Societies
}

\subsection{Introduction}

European policy-makers have decided to cut early retirement benefits in order to stimulate employment among elderly workers. The proclaimed goal is to replace an alleged "early exit culture" with a model of "active aging." At the same time, the ageism debate has pointed to the persistence of negative age stereotypes among both employers and employees (Loretto et al. 2000). Without sufficient public support, the efficacy of pension reforms aimed at deferring retirement ages seems questionable (Litwin et al. 2009). But while discriminatory age norms appear to be widespread, the actual holders of these norms have remained curiously anonymous because there is limited understanding of the pervasiveness of social norms of retirement.

Drawing on recent micro data from the European Social Survey, this chapter gathers empirical evidence on social norms and preferences concerning the timing of retirement across European societies. At the macro level, the aim is to establish empirically how country-specific institutions shape the understandings of age-appropriate behaviour. Against the background of an ongoing retrenchment of pension schemes, the question arises as to how far individuals adapt their preferences to a changing institutional and economic environment.

As to micro-level differences, one aim is to estimate the impact of social class on retirement age norms. According to the popular second-modernity theorem, class should not play a significant role here. By contrast, sociological class theory naturally presumes a close relationship between occupational position and work-related attitudes. Can individual norms and preferences concerning the appropriate age for retirement (still) be explained in terms of class divides? Furthermore, I examine the relationship between gender and attitudes towards retirement. Given that an increase in employment rates precisely among women and older workers are two current policy goals, it is timely to compare retirement age norms for men and women. Are social norms regarding the age of retirement as deeply gendered as are work biographies? Do the characteristics relevant for the molding of female age norms differ substantially from the determinants of male norms?

The chapter is structured as follows: in the next section, I review the relatively small body of literature on retirement attitudes. The state of research is highly influenced by the life course paradigm, which also originally brought the topic of age norms to the research agenda. In addition, a brief excursion is dedicated to 
discussing the most prominent approaches to the class-attitudes nexus, bearing in mind their application to the specific case of retirement age norms. The third section develops a series of hypotheses located at both the micro and the macro level. The fourth section documents the methodology employed in the following data analysis, including the treatment of the dependent variables, the statistical model, and the operationalisation of the applied theoretical concepts using data from the European Social Survey. Following this, I examine the pervasiveness of age norms on the basis of descriptive statistics. In the central part of the chapter, then, a set of two-limit tobit regression models is estimated to assess the determinants of retirement norms and preferences. The final section features concluding remarks concerning the guiding question of this chapter: namely, who favours early retirement?

\subsection{State of Research}

Social norms of aging represent an original theme of the life course paradigm (see section 2.4). In fact, the whole research field rests on the insight that instead of being a purely biological phenomenon, the meaning of age and aging is being shaped by historical and institutional contexts (cf. Neugarten $\&$ Neugarten 1986; George 1993; Mayer 2009). After sections 3.1.2 and 3.1.5 have outlined the definition and theoretical location of age norms within this study, the present section attempts to give an overview of previous findings on age norms. By and large, studies that deal with age-related norms have concentrated on three major themes: (1) The existence of age norms and their relevance as research object; (2) the changing dynamics of age norms at the societal level, and especially their relation to formal socio-economic institutions; and (3) the sources of variation at the individual level.

(1) Do age norms of retirement exist in society at all? In their pioneering study, Neugarten, Moore, and Lowe (1965: 710) draw the attention to "systems of norms which refer to age-appropriate behavior." The authors also present the first tentative evidence of consensual attitudes that suggest the existence of age norms. Arguably, these norms function as a basis for self-assessment, as people compare themselves to others (cf. Neugarten \& Neugarten 1986). More recently, Settersten (2003: 89) reports findings from the U.S. showing that 55\% (47\%) of respondents perceived a deadline for men's (women's) life course transitions. Respondents who refused to give a general answer perhaps thought the proper timing depended on individual circumstances other than sex (e.g. occupation). Of those who gave a valid answer, $63 \%$ (54\%) said that a men (women) should retire by an age between 60 and 65 years. Remarkably, the average age deadline was two years higher for men (61.3 years) than for women (59.3 years). These results suggest that age norms exist in society, prescribing a rather clear age 
range for the transition into retirement (cf. Settersten \& Hagestad 1996). Yet, these norms are not universally perceived and are less accentuated for women than for men.

Conceptually, the age-norm hypothesis is related to a broader argument concerning the ordering of life events (George 1993; Kohli 2007; cf section 3.1.2). Accordingly, the institutionalised life course prescribes a particular timing and sequencing of life transitions. As Scherger (2007) demonstrates for West Germany, even today, a clear patterning of life-transition sequences can be observed. This standardisation of temporal patterns can be linked to social norms of aging embedded in society's "moral economy." In other words, life course theory assumes that the transition from work to retirement is influenced by age-graded social norms. In fact, social norms of aging owe their popularity and relevance as a research topic chiefly to their presumed influence on actual behavior (Billari \& Liefbroer 2007; De Vart \& Liefbroer 2007).

(2) To what extent do age norms differ between societies? At the societal level, age norms have been characterised as age cultures, in the sense of "social norms, values, ideals or perceptions in society that structure the ideas of the age-work relationship" (De Vroom 2004: 8). The view that age cultures vary across countries seems rather univocal. Age cultures concerning retirement are expected to depend on the welfare system, labour-market structures, and the broader cultural codes inscribed in national historical and religious traditions.

Yet we should not expect that there was just a singular culture of aging in every society. Pathways to retirement differ greatly in the moral meaning they carry (Kohli \& Rein 1991), and living arrangements in old-age have probably become even more diverse thanks to the trend of individualisation (Higgs $\&$ Gilleard 2006). Nevertheless, it is highly plausible that different societies bear specific understandings of the appropriate timing of retirement.

How do age cultures emerge and reproduce in relation to formal socioeconomic institutions and behavioural regularities? Age norms of retirement are usually considered in the context of career patterns and the institutional framework in place, using as a reference the "golden age" of welfare capitalism. In fact, in the 1950 s and '60s, the conventional male work biography that ended with retirement at an age 65 years had actually become the overwhelming standard. Han and Moen (1999: 193) insist that the exceptional convergence of retirement ages around a single reference point was "the result of a multitude of factors coalescing and coinciding around a specific age, which in turn became defined as normative post hoc."

This account is representative of life course theory in that it understands socio-economic institutions and norms of aging as interdependent. Accordingly, the various associations within the triangle of institutions-norms-behaviour involve mutual causation. Therefore, both collinearity and endogeneity represent potential pitfalls in relying on age cultures for the explanation of 
retirement behaviour. To the degree that the incentive structure embedded in formal institutions reflects latent age norms existing in society, the effect of age norms on individual behaviour will not be distinguishable from instrumentally rational behaviour (Mortimer et al. 2005). Moreover, observed regularities in life course patterns can just as well be the consequence of normative effects as norms of early exit can be rationalisations of past behaviours or of institutionally defined age thresholds. Therefore, testing the impact of age norms on behaviour empirically is complicated.

Ingrid Esser's (2005b) study tackles the question of the determining factors of the preferred retirement age using cross-sectional Eurobarometer data. In her multi-level model, institutional and demand-side variables explain between 25 and $31 \%$ of country-level variance in retirement preferences for the male and about $22 \%$ for the female sub-sample (Esser 2005b: 30). In any event, there is a widespread belief among life course scholars that social norms are characterised by a considerable degree of autonomy, which implies that they are not susceptible to direct political manipulation (Behrens \& Voges 1996; Kohli \& Künemund 2000; Geissler 2004).

(3) Turning to the question of micro-level differences, Esser (2005b) reports that the greatest variation in preferred retirement ages is found within countries and not between countries. Ironically, the individual characteristic that was analysed first with regard to its relevance for age norms was age itself. Already Neugarten et al. (1965) point to an age-specific pattern in the internalisation of age norms. Young and middle-aged respondents revealed a considerable lack of congruence in their personal attitudes towards age constraints as compared to what they thought about other people's opinions (Neugarten et al. 1965: 715). Generally, respondents maintained that they held more liberal views than the generalised other. However, this pattern was not found among older respondents, who expressed high accordance with what they perceived as most people's attitudes. Older people thus seem to have a more realistic view of age norms, and express far more restrictive attitudes concerning age appropriateness than their younger counter-parts. The authors suggested that this overall pattern may be the result of the fact that people tend to give undue weight to the opinion of older people, who, by that token, are perceived as the defenders of social norms. In addition they emphasise the learning effects of adult socialisation, which lead to "a certain crystallisation of attitudes in the aged" (ibid.: 717). Esser's (2005b) estimates similarly indicate that age is the strongest predictor of retirement preferences on the micro level across countries: the older a person is, the later he or she prefers to retire. There is also evidence showing a close relationship between age and non-financial employment commitment (Hult \& Edlund 2008).

As already mentioned, studies on the social norms of aging regularly find substantial gender differences (Settersten \& Hagestad 1996; Settersten 2003). 
Yet, the impact on retirement norms and behavior is not well understood. Role theory and preference theory offer some intuitive explanations for traditionalist gender age norms of retirement (George 1993). Still, both accounts can be regarded as unsatisfactory in theoretical terms insofar as social context is not adequately taken into consideration (see section 3.1.5 above). In this vein, Esser (2005a: 14) exhorted that "subsequent analysis of work and retirement preferences needs to take account the gendered participation patterns related to still widely gendered labour markets, work careers and work identities."

The main place where age norms on exit from work are diffused and reproduced is probably the workplace. The literature on ageism points to substantial influence of organisational characteristics on negative stereotypes about older workers (McGregor \& Gray 2002). At the same time, there is evidence that a higher proportion of senior workers in a company is related with a higher expected retirement age among the workforce (Moen et al. 2005: 253). Notably, the literature on age norms has hardly paid attention to social class. An exception is Esser (2005), who did not find significant class effects. The lack of sociological research in this area is surprising insofar as the class-attitudes linkage is a classical problem in social theory.

\section{Excursus: The Class-Attitudes Linkage}

The question of class-graded norms goes back to Marxist theory, which sees most attitudes as a function of class situation. The preeminence of the objective distribution of the means of production over subjective ideas is a central tenet of historical materialism. For Marxist theorists (e.g. Lukász), the famous problem of "class consciousness" was to identify the necessary economic conditions for the proletariat to become a class "for itself," i.e. to develop a self-awareness as an exploited group necessary for collective action (cf. Hechter 2004; Scott \& Marshall 2005). Yet, the content of this class consciousness was seen as inherently determined by the totality of the historical process. This circular line of argument has proved misleading and its predictions false.

Neo-Weberian class theory has long abandoned the notion of an immanent class-consciousness link (Goldthorpe \& Marshall 1992: 383), thereby excluding the question of identity from the definition of social class. Unfortunately, this has led to the neglect of most cultural correlates of social class in mainstream sociological research until its revival within the works of Pierre Bourdieu. Recent work attempts to bring the normative realm back into class analysis (Devine $\&$ Savage 2000).

For the following analysis of the class-attitudes nexus, it is helpful to distinguish clearly between three normative dimensions of social life that have often been associated with class: (1) the attitudinal dimension, which refers to preferences 
and norms shared between members of a group. ${ }^{27}$ It includes work orientations, social norms, and tastes of consumption; (2) the reflexive dimension, which refers to the self-perception of individuals as belonging to a particular group, that is, to the question of identity, and more specifically to class consciousness (Savage et al. 2001; Payne \& Grew 2005); (3) the status dimension, which refers to the external perception of the members of a social group and is related to the concepts of prestige and reputation (cf. Sørensen 2001; Scott 2002).

Age norms, as a research object in this chapter, are seen exclusively as an instance of the attitudinal dimension. Social classes can differ with respect to their retirement preferences without having the self-perception of pertaining to a particular class. Analogously, it is not necessary that their reputation be valued differently by society in order to hold different social norms concerning retirement. Questions of identity or status are not pursued further here. Note that the proposed threefold distinction fulfills mainly analytical purposes and does not deny that there are important intersections and interactions between these dimensions (cf. Hechter 2004).

How then can we conceptualise the relationship between social class and preferences? An important contribution in this respect was made by Karl Mannheim. He argued, similarly to Marx, that norms and preferences are dependent on class positions (Standortabhängigkeit). "These [objective] conditions channel and motivate his [the individual's] behavior whether he is aware of them or not" (Mannheim 1992: 110). In contrast to Marx, however, Mannheim acknowledges the importance of individual agency in realising "... the fact that a class does not completely absorb and explain all actions of the concrete person" (ibid.). Individual orientations can thus depart from existing class-graded norms (Mannheim 1980: 81 f.).

Moreover, in Mannheim's theoretical reasoning (1980: 297-303), we also find the idea of a multi-layer culture in modern societies. Accordingly, the idiosyncratic norms and preferences of "primary cultural communities" co-exist and interact with an overarching societal culture. This parallels the concept of "local norms" in Bicchieri's norm theory (cf. section 3.1.2). The notion of class norms being situated on an intermediate level between individual motivations proper and societal cultures seems today still appropriate. Indeed, occupational class is often regarded as key to individual attitudes, particularly in terms of political orientations (Sørensen 2001; Hechter 2004; Svallfors 2006).

But how exactly do members of different social classes develop distinct work orientations and shared social norms? As Grusky and Sørensen (1998) set out, this link mainly works through three mechanisms: social closure, formal

$\mathbf{2 7}$ See section 3.1 .5 for details on the employed terminology. 
training, and self-selection. Social closure guarantees a limited range of social interactions within occupations. As a consequence of peer-group effects, increasing work experience therefore tends to go along with the adoption of at least part of the occupation-specific norms. Furthermore, the lengthy periods of training required to obtain formal credentials foster occupational socialisation and set the foundation for the reproduction of occupational identities (Grusky \& Sørensen 1998: 1208). Finally, preference-driven self-selection leads individuals with a similar predisposition to enroll in similar occupational tracks in the first place. In this way, a variety of plausible mechanisms contribute to the cultivation of class-specific norms and preferences. In the next section, this conception will be applied specifically to norms concerning retirement.

\subsection{Competing Hypotheses}

\subsubsection{Instrumental Work Orientations or Age Norms?}

In the economic analysis of retirement, preferences are treated as exogenously given and are assumed to be homogenous. This choice is not only a matter of econometric convenience but also reflects the supposition that differences in strategic responses to monetary incentives are more relevant than differences in preferences. The guiding idea is that homo economicus only works to earn an income, the final aim always being consumption. The restrictions imposed by this model, of retirement decisions as a purely pecuniary calculus, however, do not prevent many economists from interpreting early retirement as driven by people's low levels of attachment to work. By this token, we would expect to observe a widespread affinity to early exit from work. Indeed, there is empirical evidence which points to an average preferred retirement age well below the common statutory pension age of 65 years (Bertelsmann Stiftung 2006; AXA 2008). This leads to the following instrumental-work-orientation hypothesis:

H1a: People prefer to retire as soon as possible.

The actual degree of uniformity of people's desire to retire as soon as possible, however, is unknown. In contrast to the instrumental understanding of work in economics as a mere source of income, the sociological approach typically emphasises the intrinsic value of work to individual actors (Doherty 2009; cf. sections 2.4 and 3.1.1). The high incidence of volunteering is a case in point (Wilson \& Musick 1997; Strauß 2009). As set out above, from a life course perspective, we would expect to observe pointed age norms regarding the retirement transition. In particular, the intrinsic value of work should be 
reflected in a noticeable retention against very early retirement. Contrasting the notion of instrumental work orientations, these ideas can be translated into the age-norm hypothesis:

H1b: There are established social norms regarding the timing of retirement, and especially against very early retirement.

\subsubsection{Class, Gender, and Individualisation}

The individualisation discourse questions the usefulness of social class as a sociological category (Beck 1983), and particularly the impact of class on attitudes (cf. Scott 2002; Atkinson 2007). With respect to retirement, the proponents of a "second modernity" argue that social class has increasingly lost its power to shape identities and lifestyles in later life due to a decoupling of working and post-working life: "Variability in the material and social outcomes of individual lives can no longer be seen as resulting from stable, fixed social positions" (Higgs \& Gilleard 2006: 231). The individualisation hypothesis is based on the observation of an ongoing pluralisation of lifestyles and new living arrangements, which supposedly offer more freedom of choice to individuals than before in the overcome class society. The retirement decision, which certainly marks a profound change in lifestyle, should thus be unaffected by class membership.

$\mathrm{H} 2 \mathrm{a}$ : Class membership is not a determinant of retirement age norms.

This individualisation hypothesis stands in stark contrast to the premises of social-stratification research. As explained above, class-belonging is believed to influence the world views and preferences of the individual via work experience, peer-group effects, and shared life conditions (Grusky \& Sørensen 1998). For instance, it has recently been demonstrated how strongly social class is related to work-related attitudes (Svallfors 2006). Correspondingly, we expect retirement age norms to differ across social classes.

H2b: Class membership affects retirement age norms.

To be more specific, age norms should vary according to work strain, autonomy in the workplace, position in the command structure, and career prospects. According to a class-analytical account, we would expect position in the work hierarchy to be positively correlated with the preferred age for exit from work. At the same time, employers and the self-employed ought consequently to have a high affinity for late withdrawal from the labour market. Further, as a 
consequence of differences in work strain, we would expect manual workers to adhere to lower retirement age norms than white-collar service employees.

Patterns of labour-market participation in most advanced economies are very different for men and women, and retirement is no exception. Women withdraw from work earlier than men. Insofar as social norms match with genderspecific retirement behaviour, early exit from work should be regarded as more appropriate for women than for men. According to the "doing gender" approach (West \& Zimmerman 1987), a low work attachment can be seen as a form of gender display. The doing gender hypothesis accordingly posits a substantial gender difference in social norms of aging.

H3a: Retirement age norms differ according to gender, with early retirement being considered more appropriate for women than for men.

In this form, the assertion concerns women as a target group of social norms, whilst not referring to the sex of the actual holders of norms. From Hakim's "preference theory" (Hakim 2003, 2007), however, a more far-reaching hypothesis can be derived. In what amounts to a variation of the "doing gender" theme, she argues that there is a sizable group of "home-centered" women who affirmatively embrace their role as housewives. It follows that men and women can be expected to hold different sets of age norms regarding women's timing of retirement. Driven by home-centered women, female respondents should thus on average display a stronger acceptance of women's early exit than do male respondents: "There is only a weak link between public morality attitudes and personal preferences and goals. [...] Men and women may believe that women should be allowed to become miners, army officers or politicians without necessarily wanting to do such jobs themselves" (Hakim 2003: 340). Hence, the preference-theory hypothesis:

H3b: Women find appropriate an earlier retirement for women than men find appropriate for women.

Hakim's account suggests that preferences are an expression of free will, not imposed by society (cf. section 3.1.3). Critically, her view neglects the immediately related question of preference formation and, ipso facto, circumvents pertinent causality issues. Fortin is therefore right to ask: "Were women's attitudes formed before employment decisions - in their youth, for example-or are these attitudes subsequent rationalizations of their labor market choices?" (Fortin 2005: 420). As quoted above Hakim insists that women's preferences are only loosely connected to the valid social norms in a society. Since gendered preferences thus appear as the "natural" state of things, her view appears indeed "genderessentialist" (Crompton \& Lyonette 2005). 


\subsubsection{Age Cultures, Institutions, and Behaviour}

As set out above, life course theory assumes that institutions, behavioral regularities, and people's attitudes are interdependently related. Accordingly the institutional framework should induce a normative force that brings preferences in line with welfare-state regulations. Due to the diversity of national histories and welfare regimes, we would therefore expect to find diverse work orientations (Sivesind 1995) and age norms (De Vroom 2004) at the country level. This view seems to be quite uncontroversial. Correspondingly, age norms and preferences for early retirement should vary substantially across countries.

H4: Retirement norms and preferences differ significantly across countries.

Somewhat vaguely, the literature also refers to the phenomenon of "early exit culture" (Guillemard 2003; De Vroom 2004; Gould \& Saurama 2004; Phillipson 2004; Esser 2005b). Unfortunately, the implications of this notion have not been spelled out at any great length, but for the most part, the term seems to refer to the presumed impact of formal institutions on social norms and values. More to the point, Mortimer et al posit that "[a]ge norms may arise in response to institutional regulatory schemes and to the rewards and punishments that are linked to compliance" (Mortimer et al. 2005: 177). That is, individuals directly adjust their norms of age-appropriate behaviour to the institutionally defined pay-off scheme for the life transitions in question. Since modifications in the institutional opportunity structure supposedly translate immediately into changes of preferences, we shall called this the preference-regulation hypothesis.

H5a: Retirement preferences in a society vary according to the monetary incentives offered by the welfare state for early retirement.

As discussed above, the institutionalised life course theorem implies a different, albeit compatible, take on the institution-attitudes nexus. Arguably, the age boundaries established by public pension schemes exert a normative effect over and above the financial incentives inherent in them (Esser 2005b: 30). This symbolic significance of age markers beyond their pecuniary relevance makes them an effective regulatory device (Kohli 1993). Besides, the functioning of age thresholds is far easier for citizens to grasp than the technicalities involved in pension rules, such as discounting and indexation. In short, the normative-ageboundary hypothesis asserts that the statutory normal retirement age serves as a genuine benchmark for retirement preferences.

H5b: The normal retirement age of pension schemes exerts an influence on retirement norms, over and above the inherent monetary incentives. 
In this context, it is important to clarify that the early retirement incentives manifest in pension schemes are, in principle, independent from the fixation of a normal retirement age. Of course, empirically, there is a large degree of covariation, but theoretically, identical incentive schemes can exist that define different normal retirement ages. ${ }^{28}$ However, the same is not true for eligibility ages, which are a crucial element of early retirement incentives. In contrast to $\mathrm{H} 5 \mathrm{a}$, the emphasis on the saliency of the normal pension age implies that $\mathrm{H} 5 \mathrm{~b}$ assumes only a loose association between pension incentives and retirement attitudes.

The notion of "early exit culture" has not only been associated with socialsecurity incentives ( $\mathrm{H} 5 \mathrm{a}$ ) but also with the impact of labour market conditions on retirement attitudes. In fact, according to a simplified version of the revealedpreference theorem, a high level of unemployment indicates that people have an average reservation wage that is higher than the market wage. Insofar as unemployment and retirement from a purely economic point of view are similar states of inactivity, this revealed-work-preferences hypothesis posits,

H6: Norms of late exit are negatively associated with the unemployment rate.

It was already suggested above that the life course approach conceptually relies on the various interactions among the triad of institutions, attitudes, and behaviour. Accordingly, another mechanism by which attitudes towards retirement can vary internationally is mere convention. Analogous to Weber's ideal type of traditional action, the idea here is that people affirmatively adjust their work-related norms and values to the life course patterns that they observe among previous generations. Then we should find at the macro level that the molding of retirement age norms at a particular moment is a function of antecedent retirement behaviour of older cohorts. In technical terms, this would mean that country differences in age norms can be explained by a lagged effect of the effective retirement age.

H7: Retirement age norms follow the retirement behaviour of the foregoing generation.

28 To illustrate the argument that the statutory pension age is essentially a reference point for benefit calculation, imagine two pensions systems, A and B. Both are identical, except that $A$ foresees a normal retirement age of 65 years and $B$ of 66 years. Let us assume that both have an adjustment factor of 5 percent for each year of retirement before the normal retirement age. For the sake of the argument, let us further ignore inflation, taxation, pension benefit indexation, and mortality. Under these conditions, if B offers pension benefits at the normal retirement age of 66 years that are 5 percent higher than they are in A at age 65, the economic incentives for early exit in A and B are in fact the same while having different normal retirement ages. 
The bottom-line of this age-norms-as-conventions hypothesis is that, everything else being equal, age norms may simply change because of the changing retirement practices in foregoing generations of retirees. In this view, the expansion of early retirement as a behavioural regularity - which in turn may be due to an exogenous shock, like a shift in pension rules - induces a persisting change in retirement preferences. Perhaps it is this peculiar mechanism that the evasive label "early exit culture" would actually fit best.

However, there are some pertinent counter arguments to the above hypotheses. Accordingly, in spite of the interrelatedness of formal and informal institutions, norms concerning the life course are not susceptible to direct political regulation. Neither can age norms be expected to simply adapt to behavioural patterns of the past. For example, Esser (2005b: 30-33) finds no evidence to support the idea that either welfare state generosity or high unemployment among the elderly would go along with a widespread preference for early exit from work.

Moreover, in spite of some responsiveness to material incentives, it seems reasonable to assume that cultural norms of aging are relatively inert (Mortimer et al. 2005). The effect, if any, that institutional opportunity structure has on social beliefs and values is probably indirect and lagged rather than direct and immediate. Hence, the social expectations around retirement likely reflect, at most, a skewed image of the socio-economic circumstances of the past. In conclusion, the question of the strength and immediacy of institutional impact cannot be decided on theoretical grounds but must be submitted for empirical testing in the remainder of this chapter, bearing in mind the expected collinearities between age norms, institutions, and behaviour.

\subsection{Data and Methods}

\subsubsection{Data and Sample}

In its third round, the European Social Survey (ESS) featured a rotating module on "The Timing of Life," which consists of a series of questions on age-related attitudes. Interviews were conducted between August 2006 and December 2007. The ESS's strictly comparative survey design converts this prize-winning survey project into a particularly well-suited data source to study age norms in a multi-country framework. ${ }^{29}$ Besides asking for the respondents' opinions on

29 The ESS won the 2005 Descartes Research Prize. For further details, see the web page of the project: <www.europeansocialsurvey.org> 
earlier life events, such as parenthood or employment entry, there is also a set of questions on retirement transitions, which will be used in the present analysis. The sample is restricted to respondents in the 14 participating Western European countries: Austria, Belgium, Denmark, Germany, Great Britain, Finland, France, Ireland, the Netherlands, Norway, Portugal, Spain, Sweden, and Switzerland. ${ }^{30}$ Eastern Europe is not considered here for the reasons explained in the introductory chapter.

Only respondents aged 50 and above are selected in the sample because previous research had shown that attitudes towards retirement are not welldefined among young and middle-aged persons, who are often ill-informed about pension issues. Dealing with cross-sectional data, it was further found to be preferable to exclude the oldest interviewed respondents from the sample in order to limit any bias resulting from period effects or differential mortality. In consequence, the final sample comprises all respondents born between 1930 and 1957. As the present analyses put a major emphasis on the gender divide, it is very convenient that all ESS questions related to age norms were posed to men and women separately. For this purpose, a split-ballot procedure with random assignment was used. That is, one half of the respondents (men and women) have been asked about their attitudes concerning men's life transitions and the other half, on women's.

To start with, the module includes the question, "In your opinion, what is the ideal age for a man/women to retire permanently?" In case of doubt, retirement is specified by the interviewer as giving up paid work. In the words of Settersten and Mayer (1997), the ideal age of retirement counts as an optimal age norm, as it comprises notions about the "best" or "preferable" age to experience a particular life event. However, such optimal age norms are not necessarily closely linked to actual behaviour (Marini 1984). Instead, prescriptive and proscriptive age norms are likely more relevant, as they entail "shared expectations about when certain transitions 'should' or 'should not' occur" (Settersten \& Mayer 1997: 242). Proscriptive norms regarding the timing of retirement are captured in two other items from the ESS module analysed below. They ask respondents the ages before which someone is too young to retire permanently and after which one is too old to work. In detail, one question reads, "Before what age would you say a man/woman is generally too young to retire permanently?" It captures the view of the respondents on the youngest appropriate age for retirement. Correspondingly, the oldest appropriate retirement age is asked

30 The sole exception is the Cypriote respondents, who have been exempted from the sample because the macro indicators applied in the second part of the analyses were not available for Cyprus. 
for in the following question: "After what age would you say a man/woman is generally too old to be working at least 20 hours a week?"

Together, these three items appear as appropriate tools for the measurement of the concept of interest, i.e. social norms of aging. By explicitly referring to the generalised other, the wording of the latter two items is clearly focused on agegraded social norms as opposed to narrowly-defined individual preferences. The question on the ideal age, by contrast, has a more personal focus that likely entails individual work orientations. Jointly, these instruments are qualitatively superior to those used in most of the previous literature on retirement age norms, which were almost exclusively based on questions regarding the ideal or optimal age. As an analytical apparatus in the context of this study, they are still limited, though. Ideally, additional survey questions would make explicit reference to the personal situation of the respondent (Hakim 2003). In this way, the analyst would be able to isolate external social norms from internalised norms, thereby obtaining a richer picture of individual attitudes towards retirement. For the class-analytic research questions dealt with in this chapter, it would be particularly desirable to differentiate the items not only by gender but also by occupational groups.

\subsubsection{Statistical Model}

This section discusses the nature of our three dependent variables, ${ }^{31}$ and sets out the reasons for choosing a tobit censored regression model for the multivariate statistical analysis. In principle, the three dependent variables are intervalscaled and thus susceptible to analysis through simple OLS. In the introduction to this survey section, respondents were told to give an approximate age for each of the items, and interviewers were instructed to ask for a specific age when respondents answered with an age range. This procedure thus yielded point data for the majority of respondents. However, a serious shortcoming of applying the standard linear model to the data in hand arises from the considerable share of nontrivial non-response, e.g. people answering with "never too old" on the question when a man is too old to work or "never too young" in response to at what age one is too young to retire (see section 4.5 .1 below). There are some cases coded as "should never retire permanently" in response to the "too young" and "too old" questions, also, and for each item, there are a minority of respondents (less than 1\%) who answered that one "should never work/be in

31 Scaling analysis revealed that the three items on retirement attitudes do not measure the same thing. 
paid work." ${ }^{2}$ In OLS, all these observations would either have to be dropped or imputed, thereby losing valuable information conveyed by these extreme responses.

A more elegant approach is offered by the tobit regression framework. The tobit model refers to a family of estimators particularly designed for corner solutions or censored dependent variables (cf. Breen 1996; Long 1997: chap. 7; Wooldridge 2006: chap. 17). It was developed by the economist James Tobin (1975), who was confronted with a strong lumping of the distribution at value zero when analysing the consumption of durable goods. The intuitive assumption of the model is that there actually exists a true value corresponding to the censored cases that we are unable to observe. In technical terms, the method amounts to estimating the regression coefficients for an underlying latent variable rather than for the observed values. This is achieved by, in the words of its inventor, "a hybrid of probit and multiple regression model" (Tobin 1958: 25).

In the present case, the two-limit tobit model (Long 1997: 212) will be applied. It represents an extension of the simple tobit model for cases in which the dependent variable is subject to both an upper and a lower limit (Rosett $\&$ Nelson 1975). Given the lower and upper boundaries $\tau_{\mathrm{L}}$ and $\tau_{U^{\prime}}$ our observed dependent variable $y$ is determined by

$$
\begin{array}{ll}
\tau_{L} & \text { if } y^{*} \leq \tau_{L} \\
y=y^{*}=x \beta+\varepsilon i & \text { if } \tau_{L}<y^{* *}<\tau_{U} \\
\tau_{U} & \text { if } y^{*} \geq \tau_{U}
\end{array}
$$

We observe the latent variable $y^{*}$ directly only if it falls between the two limits, and we otherwise observe either $\tau_{\llcorner}$or $\tau_{U}$. Thus, our sample is split into three fractions. Correspondingly, the likelihood function includes three components: one for observations censored from below, one for observations censored from above, and one for non-censored observations. Long (1975: 212) shows that the logarithm of then becomes

$$
\ln L=\sum_{\text {Lower }} \ln \Phi\left(\frac{\tau_{\mathrm{L}}-\mathrm{x} \beta}{\sigma}\right)+\sum_{\text {Unceensored }} \ln \frac{1}{\sigma} \phi\left(\frac{y-\mathrm{x}_{\mathrm{i}} \beta}{\sigma}\right)+\sum_{\text {Upper }} \ln \Phi\left(\frac{\mathrm{x} \beta-\tau_{\mathrm{U}}}{\sigma}\right)
$$

where and $\Phi$ refer to the normal cumulative density function and the normal probability function respectively and $\sigma$ is the standard deviation of the error term.

As Rosett and Nelson (1975: 142 f.) set out, this function has the desirable property that the exact non-limit (out of bounds) values of $y$ do not have to

32 For illustrative reasons, these response categories have not been itemised in the descriptive figures of section 4.5.1. 
be known provided that we know the limits of . It can be maximised using the Maximum-Likelihood estimator. In the present application, it has been chosen to treat responses as point data in the interval ages of 40 to 80 . Correspondingly, "never" answers are treated as either censored from below ("should never work") or from above ("never too old to work") respectively. At the same time, this method implies a straightforward handling of outliers, hence avoiding a distortion of the results by a few deviant cases. ${ }^{33}$

Note that the interpretation of tobit regression results can be undertaken by reference to different marginal effects, depending on which elements of the likelihood function are of greatest interest. In the present case, the fraction of censored cases is quite limited, such that the predicted scores on the underlying latent variable are actually corresponding quite closely to the point data directly observed in years of age. Therefore, in the discussion of the findings below, the coefficients are displayed as per unit changes in the assumed underlying continuous variable, which, for simplicity, are also referred to as years. It should also be noted that standard errors are corrected according to the stratified sample design using the clustered sandwich estimator and that weights are applied in order to correct for unit non-response.

\subsubsection{Operationalisation of Micro-Level Variables}

With regard to the right-hand side of the equation, there is a great variety of factors that may theoretically be related to retirement-related norms and preferences. The next two sections set out the operationalisation of the covariates of interest as well as of the included control variables. Note that all missing values have been imputed using multiple imputation and that standard errors of all presented estimates have been corrected accordingly. ${ }^{34}$

Social class: Social class is measured according to the European Socioeconomic Classification (ESeC). The coding of social class is based on the characteristics of the main job for the employed; otherwise, and this mainly applies to the retired respondents, the basis is the last job held. See section 3.2.2 for further details.

33 For the ideal age and the age after which one is too old to work, those narrowly defined outliers represent less than $1 \%$ of the valid responses. In case of the age before which one is too young to retire, there are $3 \%$ and $7 \%$ of outliers for women and men respectively (most of them below the 40 year threshold).

34 Specifically, the imputation procedure employs Patrick Royston's ice module for Stata, cf. Royston (2004). 
Age: It is a recurrent finding that preferred work-exit age is sensitive to age (Engstler 2004; Esser 2005b). In particular, people tend to mention a later retirement age as they age themselves. This could be explained by learning processes. Indeed, it seems reasonable to assume that once people approach retirement they form more realistic beliefs about the possibilities and financial implications of retiring early and hence adapt their expectations to the perceived income constraints. Age is measured in the ESS on a monthly scale; it is implemented into the model in both linear and quadratic form in order to account for possible non-linearities.

Employment status: Employment status is an important determinant of retirement norms and preferences. From a revealed preferences perspective, we should expect unemployed persons as well as homemakers to have a lower work attachment than employed persons. For retirees, in turn, the work attachment could depend on the very experience of retirement. For instance, it has been shown that many people live a honeymoon phase of increased life satisfaction immediately after retiring.

However, this regressor is potentially endogenous because people with a lower work attachment are also more likely to be retired at any given moment. Thus, the coefficients from of a simple regression would be biased. The problem of causality is manifest in all analyses of the linkage between attitudes and labour market participation (Fortin 2005). The possibility of circumventing this caveat using an instrumental variables estimator has been explored but was eventually discarded. The reasons are twofold: firstly, this quasi-experimental approach relies on identifying at least one valid instrument. Such a variable needs to be correlated with the endogenous regressor, conditional on the other covariates, but must not be causally related with the error term of the outcome equation. Yet, it proves to be a nearly impossible challenge to find such an exogenous variable, and all the more in a cross-sectional data set. In the present example, the factors that enter the selection equation (here, factors that predict employment status) also influence the population outcome equation (here, attitudes towards retirement).

Secondly, even if it were possible to fix the obvious endogeneity with respect to employment status, the very same problem would still be present for most of the other variables of interest. For example, it was mentioned above that social class is potentially endogenous to retirement preferences, because the choice of a profession is also a choice of a particular career path. Educational and job choices are a function of one's early life work-leisure preferences in the first place. Here, as in the vast majority of sociological research settings, we are utterly unable to neatly model the underlying process in terms of strict causality. Given this situation, the attempt to adjust the employment status coefficient would only conceal the basic constellation of mutual causation and omnipresent endogeneity. Instead of estimating causal effects, the more modest objective 
here is to identify the conditional expectation function (cf. Ichino 2008; Angrist \& Pischke 2009: 29-40), i.e. the model that gives us the best predictor of our dependent variable.

Health: The respondent's health status is captured through a dichotomous variable indicating if self-perceived health is less than good. Evidently, ill health increases work strain and strongly increases the risk of early exit. To a certain extent, health differences are thus also captured in the respondent's employment status. However, it is reasonable to expect that deteriorating health does not lead to immediate retirement but will often first be reflected in the intention to withdraw soon. Among retirees, similarly, worsening health is probably subjectively associated with the work biography. It would not be surprising if under these conditions, people re-evaluate their retirement decision, wishing they had withdrawn earlier.

Trade union membership: The effect of belonging to a trade union can reflect two distinct mechanisms, namely a selection effect and a causal effect. Both point in the direction of early exit. Firstly, the decision to sign up for trade union membership is likely to be driven by a critical attitude towards the employment relationship. The labour movement is founded on its opposition to the capitalist organisation of work, and trade unions have been involved in a class struggle with employers for centuries. Therefore, the average unionised worker is likely to seek earlier retirement than non-unionised employees. Secondly, being a trade union member strengthens the position of workers in the firm. We therefore expect union members to be able to achieve more favourable conditions for early retirement than non-union-members..$^{35}$ To the extent that work-exit norms are affected by rationalisations of the foreseeable timing of retirement, this should result in the greater approval of early work withdrawal among unionised workers.

Education: In nearly all empirical studies on normative issues, education is one of the strongest single predictors. However, the precise mechanisms through which education matters for work-related attitudes are not well understood (Ortega \& Polavieja 2012). Educational attainment might affect retirement norms through its relationship with labour-market position, but this dimension should be captured more adequately by class membership. Education is nonetheless of genuine importance here because a higher-level education translates into a later entry into paid employment. To the extent that work-related norms are conditional on the duration of careers, the length of the educational career

35 If, on the other hand, the worker would like to stay longer on the job, trade unions can be expected to advocate the rights of the worker, thereby protecting them from involuntary early exit (Teipen 2003). 
should be positively associated with norms of late exit. A high number of working years, which itself is unknown in the data set, may also go along with diminishing motivation and growing weariness of work. Correspondingly, years of full-time education rather than level of education is here used in the operationalisation. What is more, it is possible that a better education leads to more egalitarian gender norms. Anecdotal evidence suggests that a more liberal world view goes hand in hand with a longer time spent in modern educational systems. Hence, education should play a crucial role to the extent that age cultures are influenced by gender and family norms. Of course, gender norms target not only female but also male behaviour. Nevertheless, it can be be argued that the male life course is a less contested normative construct than the female life course. As a consequence of rapid change and greater heterogeneity in women's career patterns, we should thus expect education to be a stronger predictor for age norms related to women's retirement than for those related to men.

Job quality: The expected effect of social class is arguably partially linked to differential working conditions and job satisfaction. For employed respondents, information on job satisfaction is available in the ESS and will be used to scrutinise the social mechanism by which social class affects retirement preferences. Three variables have been selected: satisfaction with one's job is measured on a scale running from zero ("extremely dissatisfied") to ten ("extremely satisfied"). Respondents are further asked how much of the time they find their job (a) interesting and (b) stressful. Answers are given on a scale from zero ("none of the time") to six ("all of the time"). The latter variable is entered in both linear and quadratic form in order to detect non-linearities: more stressful jobs might also be more stimulating and therefore more attractive (Blekesaune $\&$ Solem 2005).

Family of origin: In sociology as well as in psychology it goes unquestioned that most social and moral norms are formed in early childhood and adolescence (Marini 1984). Accordingly, the family of origin plays a major role in shaping the individual's primary orientations and values. It follows that it might be relevant for retirement attitudes, too. Therefore the model controls for the father's level of education and for the mother's employment status when the respondent was 14 years old as proxies for family background effects. A working mother should lead respondents to give a higher retirement age norm for women. As no detailed information on parents' occupation is available, the father's level of education is used as a proxy for class origin.

Other covariates: Household income is measured in natural logarithm form using an equivalence scale of the square root of the household size. The number of grandchildren is taken into account, because their presence may provoke the wish to retire earlier. Furthermore, family situation is included, measured as a set of dummies that simultaneously captures marital status and the partner's 
employment status (if present). ${ }^{36}$ This variable is intended to account for the attitudinal dimension of coupled retirement dynamics (see section 3.1.4). Accordingly, we expect to observe the interdependence of retirement attitudes in the household, i.e. a retired spouse should lead to lower work attachment.

\subsubsection{Operationalisation of Macro-Level Variables}

Change and level of pension wealth: As discussed above (see section 2.2), pension wealth measures the present value of pension-benefit entitlements, taking account of discounting, mortality and indexation of pension payments (for a formal definition cf. OECD 2005a; Queisser \& Whitehouse 2006a). From a micro-economic labour-supply perspective, it provides an adequate measure of the incentives scheme an average earner faces at the end of working life. Two measures derived from this concept are used here, both of which are provided by Edward Whitehouse (2006) in a special draft issue of the OECD's Pensions at a Glance series: namely, the change in pension wealth as a consequence of postponing retirement from age 60 to 65, measured as a percentage of individual earnings, and the level of pension wealth at age 60, expressed in multiples of individual earnings. The indicator is calculated on the basis of the pension rules effective during the early 2000s. However, this kind of reference period gives only a rather crude orientation of the legal conditions, as pension rules typically change gradually and apply differently to different social groups (depending on cohort, sex, occupation, etc.). Some imprecision notwithstanding, this measure can be regarded as the single best comprehensive indicator of the relative generosity of pension systems towards early retirement available for a large number of European countries.

Normal and minimum pension age: Pension systems also differ with respect to statutory retirement ages. Although in most countries the normal pension age for the cohorts in our sample was still 65, there a few exceptions to this: it was higher in Norway (67 years) and in Ireland (66 years), while the official retirement age in France was still only 60 years. The minimum age refers to the earliest age at which a public old-age pension can be drawn upon. On this variable, country variation is larger. Early retirement provisions exist partly within the regular oldage pension system, partly as separated schemes. Moreover, not all countries offer the possibility to be eligible for an old-age pension before the normal retirement age. Early eligibility ages, within this definition, vary between 55 and 65 years.

36 Civil partnerships are treated as equivalent to marriage. The employment status of the partner distinguishes between active (working or unemployed and actively looking for job), retired, and inactive (unemployed and not looking for work, homemaker, retired, or other). 
Neither unemployment nor disability benefits are taken into consideration here.

Average age of retirement: It has been argued above $(\mathrm{H} 7)$ that the average exit age from the labour market in a given country can have an impact on individual retirement norms and preferences. To test if age cultures depend on the actual age of work withdrawal of the foregoing retirement cohorts, macro-level data on country-specific retirement ages are inserted into the multivariate regression model. The variable, which is taken from the OECD, is coded such that each individual is assigned the average retirement age for the year when he or she turned 50 years of age. ${ }^{37}$ For example, to the oldest cohort, which was born in the year 1940, corresponds the average retirement age of the year $1990 .{ }^{38}$ By means of this lagged variable, the impact of the behaviour of the foregoing retirement cohort can be accounted for in the regression, while avoiding endogeneity. Even though this is a macro indicator, there is considerable intra-country variation owing to cohort differentiation. As set out above (see section 3.3.1), the OECD retirement-age indicator is based on aggregate cohort-adjusted time-series data from national labour-force surveys and considers labour market withdrawal between age 40 and age 80 .

Unemployment rate: The unemployment rate is the most commonly used indicator for labour market conditions and will be employed in this study to test H6. I use data provided by Eurostat within the framework of the sustainabledevelopment indicators. The main advantage over the comparable OECD data is that the Eurostat database allows better targeting the relevant age group, namely the 50-64 year olds. It is based on the standard ILO definitions and refers to the average of the years 1996 to 2006.39

\subsection{Descriptive Findings}

The following section explores the pervasiveness of age norms and the variability of these norms across various socio-economic dimensions by means of summary statistics. For the calculation of means, imputed values have been used for "never" answers (see foregoing section).

37 The equivalent indicator by Eurostat provides information on average retirement ages only from the year 2001 onwards.

38 As the measurement relies on quinquennial age groups, in this example the indicator would in fact be based on the labour-force surveys 1985-1990. As the German data refer to East and West Germany together, this data is missing for the five years after unification. The value for 1996 has therefore been imputed to the cohorts 1940-45.

39 For the years prior to 1996, much data was missing in the data base. In the present operationalisation, the only missing data points were for Norway for the years between 1997 and 2003, which have been imputed using the mean of the adjacent data points. 
Table 4.1

Summary Statistics, Retirement Age Norms, by Gender.

\begin{tabular}{|c|c|c|c|}
\hline SURVey Question & TARGEt Gender & $\begin{array}{l}\text { MEAN* } \\
\text { (IN YEARS) }\end{array}$ & $\begin{array}{l}\text { STD. } \\
\text { ERR. }\end{array}$ \\
\hline $\begin{array}{l}\text { "In your opinion, what is the ideal age } \\
\text { for a man/woman to retire permanently?" }\end{array}$ & $\begin{array}{l}\text { Men: } \\
\text { Women: }\end{array}$ & $\begin{array}{l}61.34 \\
58.78\end{array}$ & $\begin{array}{l}.127 \\
.128\end{array}$ \\
\hline $\begin{array}{l}\text { "Before what age is man/woman } \\
\text { too young to retire?" }\end{array}$ & $\begin{array}{l}\text { Men: } \\
\text { Women: }\end{array}$ & $\begin{array}{l}52.80 \\
50.02\end{array}$ & $\begin{array}{l}.174 \\
.240\end{array}$ \\
\hline "After what age is a man/woman too old to work?" & $\begin{array}{l}\text { Men: } \\
\text { Women: }\end{array}$ & $\begin{array}{l}64.58 \\
59.86\end{array}$ & $\begin{array}{l}.132 \\
.147\end{array}$ \\
\hline
\end{tabular}

Source: ESS 3 2006; * weighted means.

\subsubsection{First Evidence: Too Young to Retire? Too Old to Work?}

Table 4.1 gives an overview of the three items relevant for retirement. Recall that the sample comprises respondents between 50 and 77 years of age in the Western European countries participating in the third round of the European Social Survey in the year 2006. In general, the data show that age norms are favorable towards early exit from work. While the mean ideal age for retirement is 61 years and four months for men, it is two-and-a-half years lower for women (58 years and nine months). As for the lower retirement age boundary, the mean response is 52.8 years among men but only 50 years among women. The gender gap for this proscriptive age norm is thus wider than for the ideal age; but the largest gender difference is found for the age after which a worker is considered too old to retire. While the mean response for men is $641 / 2$ here, women on average are held to be too old to work already when reaching the age of 60 years.

Most importantly, retirement age norms in Western Europe prescribe an earlier retirement for women than for men. In line with hypothesis $\mathrm{H} 3 \mathrm{a}$, norms of retirement seem to reflect the gendered nature of labour market participation. In each of the three dimensions, there is a highly significant difference between male and female age norms of retirement.

Equally remarkable is the orderliness of these norms of career exit. For both women and men, the mean ideal age for retirement lies between the age before which one counts as too young to retire and the age after which one counts as 
too old to work..$^{40}$ But the ideal age lies much closer to the latter than to the former, especially for women. In fact, for women there is only one year between the ideal age for retirement and being too old to work. Given the fact that not many old-age pensions allow for eligibility before age 60, it appears that for women there is a particularly narrow age corridor in which economic conditions and social norms of aging coincide.

It is worth examining the response patterns in more detail. Figure 4.1 shows the distribution of responses on the ideal age for retirement in histogram form.

A first thing that catches the eye is the strong concentration of answers at single ages. With respect to men's retirement, about one-third of respondents said the ideal age was 60 years and more than every fourth situates it at 65 years. Overall, more than two out of three respondents put the ideal age of retirement for men between 60 and 65 years. There are few people that mentioned a lower ideal age. Analogously, less than $10 \%$ of respondents name an ideal age above 65 years. For women, although the modal answer -60 years of age equally comprises a third of respondents, the ideal age of retirement is slightly less uniformly defined. This is mainly due to a higher share of respondents that situate the ideal age for female below 60 years, most of whose responses cluster at exactly 55 years. In turn, only one in seven respondents set the ideal age of retirement for women at 65 .

Figure 4.2 shows the distribution of people's opinions about the earliest appropriate age for retirement. Remarkably, there is less consent on the lowest appropriate retirement age than on the ideal retirement age. The dispersion of age categories is much greater. For men, still, $68 \%$ of the given answers are concentrated between 50 and 60 years. While the most frequently mentioned minimum retirement age for both men and women is 50 years, there are also important gender differences.

Particularly, early retirement is generally found to be more appropriate for women. Put another way, nearly $60 \%$ of respondents expressed the opinion that a woman is not too young to retire at 50 years of age; including a considerable proportion (10\%) who think that a woman is never too young to retire. Although this could in principle also be the manifestation of a very liberal world-view (i.e. rejection of age norms), the fact that this response was clearly rarer for men than for women indicates its meaning as a gendered norm against the late retirement of women.

Turning to the third and final retirement age-norm item under analysis, figure 4.3 shows that roughly four out of five respondents agree that someone is too

$\mathbf{4 0}$ Note that the means of the latter variable are slightly downwards biased due to the imputation of "never" answers. 

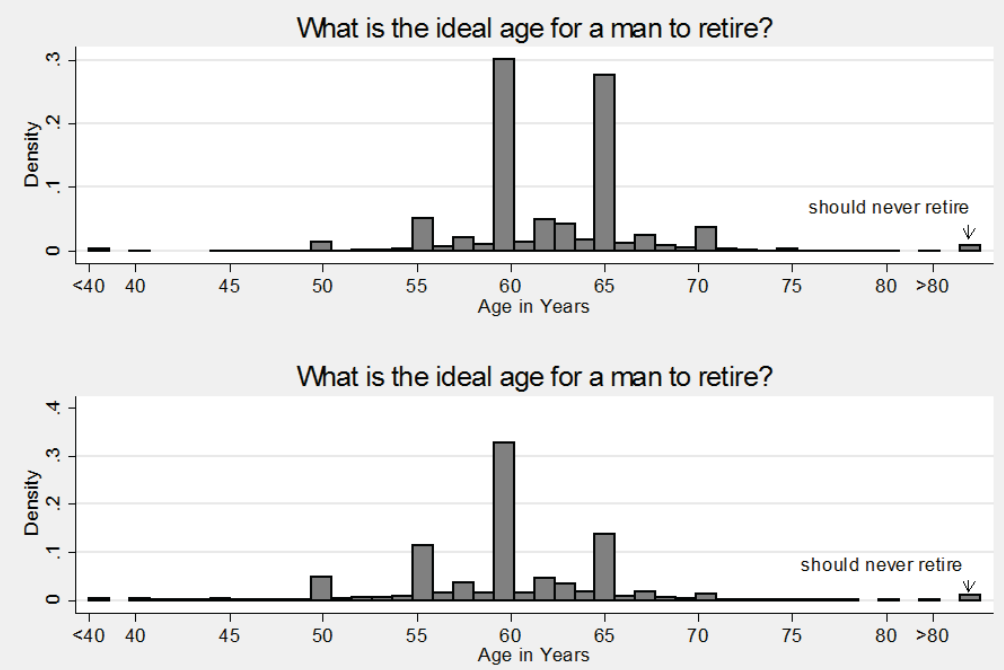

Source: ESS 3.2 2006; own calculations

Fig. 4.1 Ideal Age for Retirement for a Man/Woman.

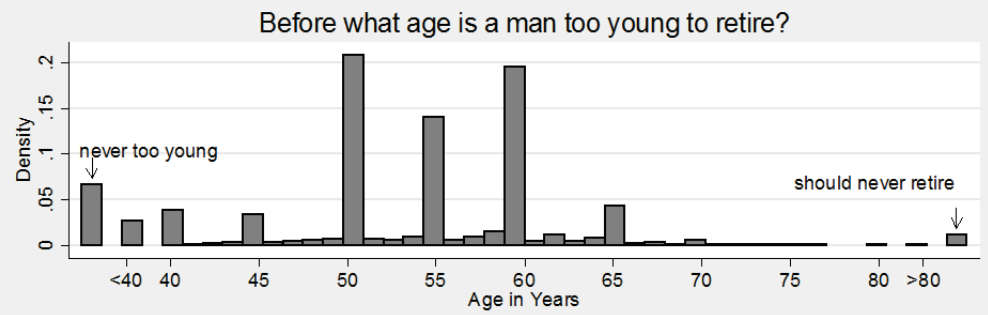

Before what age is a woman too young to retire?

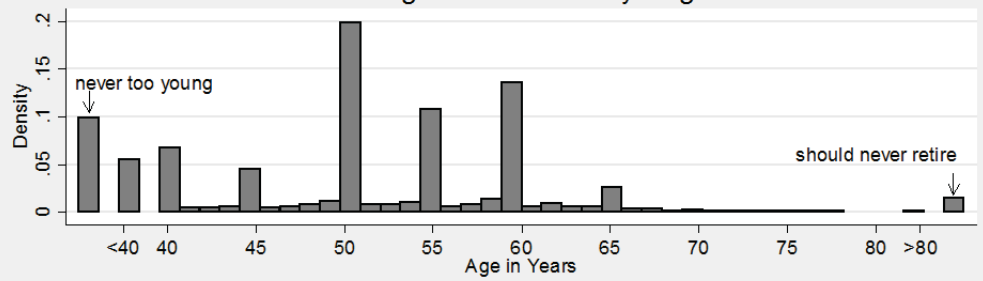

Source: ESS 3.2 2006; own calculations.

Fig. 4.2 Age Before which a Man/Woman is Too Young for Retirement. 

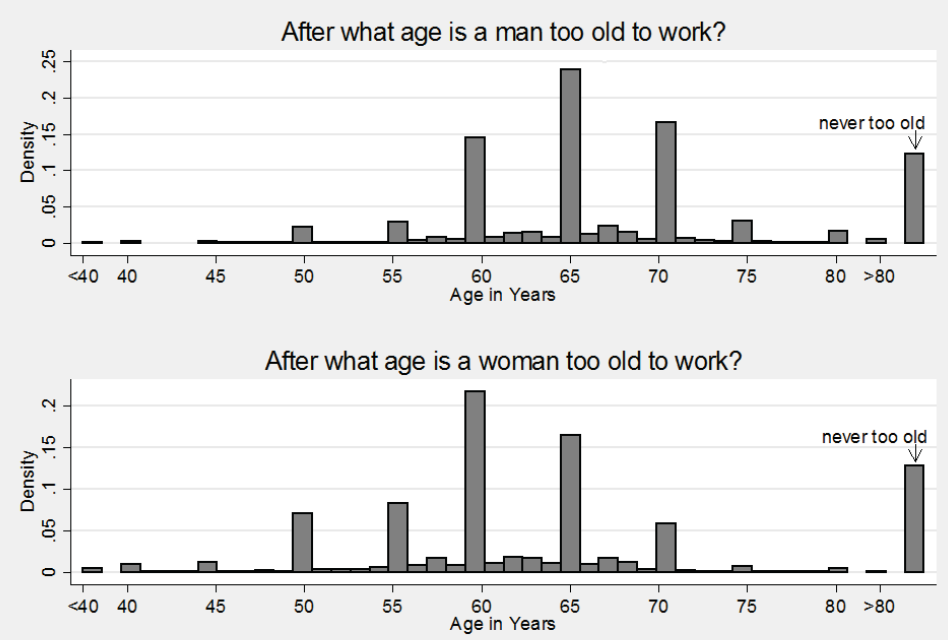

Source: ESS 3.2 2006; own calculations.

Fig 4.3 Age After which a Man/Woman is Too Old to Work.

old to work when he or she is over 70 years old. With regard to men's exit from work, the most common answer is that one should leave the job by age 65 , but interestingly another sixth of the respondents think that working until 70 is just fine. Overall, more than $40 \%$ of respondents do not think that a man over 65 is too old to work, whereas only one out of four do so for women. Nevertheless, almost $15 \%$ support the opinion that women are never too old to retire, a slightly larger proportion than for men. On the other end of the spectrum, less than $30 \%$ gave a maximum retirement age for men below 65 years, whereas the majority of respondents did so for females. The modal age for women's latest retirement is 60 years.

One general finding from the analyses so far is that people think of the life course in strongly quinquennial terms. Despite the openness of the survey questions, there is a massive clustering of answer at quinquennial ages. This pattern highlights the fundamental insight that social aging is a non-linear process. It also points to the relevance of institutional effects. Since eligibility ages in most European pensions systems have been fixed at 60 and/or 65 years, the normative age boundary of retirement - as a mental reference point - also tends to be situated at these particular ages. Modern retirement as a status configuration appears to be shaped by the benefit rules of the welfare state.

Another striking piece of information is the relatively low share of people who were unable or unwilling to provide a valid answer to the analysed survey questions. The low incidence of non-response underlines the salience of age 
norms. Even when including all "never" answers, missingness is still surprisingly modest, with rates being somewhat higher for female than for male retirement norms. The weighted proportion of respondents who gave an answer that is quantifiable in years is $84.4 \%$ for men's ideal retirement age and $76.7 \%$ for women's ideal retirement age. Among the two other items the corresponding share is similarly high: 85.8 and $74.8 \%$ for the age before which men and women respectively are too young to retire; 80.9 and $75.8 \%$ respectively for the age after which men and women become too old to work. Note that the comparatively low number for men on this variable is due to the many respondents stating that men are never too old to work.

Those numbers are considerably higher than those reported by Settersten and Hagestad (1996) (see section 4.2). In all likelihood, this discrepancy is related to the fact that the Chicago study used by the authors included adults from all ages. Only a third represented persons aged older than 50. Among the missing values are probably a considerable number of people who believe that the adequate timing of retirement depends on individual circumstances.

Overall, the high degree of social consensus expressed in the response pattern supports the hypothesis that age norms of retirement are highly pervasive. At the same time, age norms about men are more widely shared than age norms about women. On all three items the variability of answers is larger when the focus is on female labour market participation and non-response/indifference is higher. This can be interpreted as the normative analog of the fact that female career trajectories are still less standardised than male ones. Moreover, proscriptive norms are less generalised than the optimal age norm expressed in the question on the ideal retirement age. People seem to have more consensual opinions about which retirement age they prefer than about which retirement age they do not approve.

As an interim conclusion, the data give substantial credibility to the agenorm hypothesis $(\mathrm{H} 1 \mathrm{~b})$ and the ageism discourse, because a large majority of West Europeans indeed hold explicit retirement age norms. Nevertheless, the configuration of age norms does not unambiguously identify one particular year in life as appropriate for retirement. Instead, there exists a rather broad age span for adequate retirement timing that ranges over 10 to 15 years. This heterogeneity could lead some observers to deny the existence of age norms on the basis that retirement attitudes are not universally shared. However, age tolerance is clearly bounded. For instance, the findings show that $80 \%$ of respondents agree that someone is too old to work when he or she is over 70 years old. And nine out of ten respondents agree that a man is too young to retire before age 40 .

When comparing the three normative dimensions of retirement, it is significant that the norm on the oldest age for retirement tends to fall precisely into the age range that according to policy makers should be the normal time 


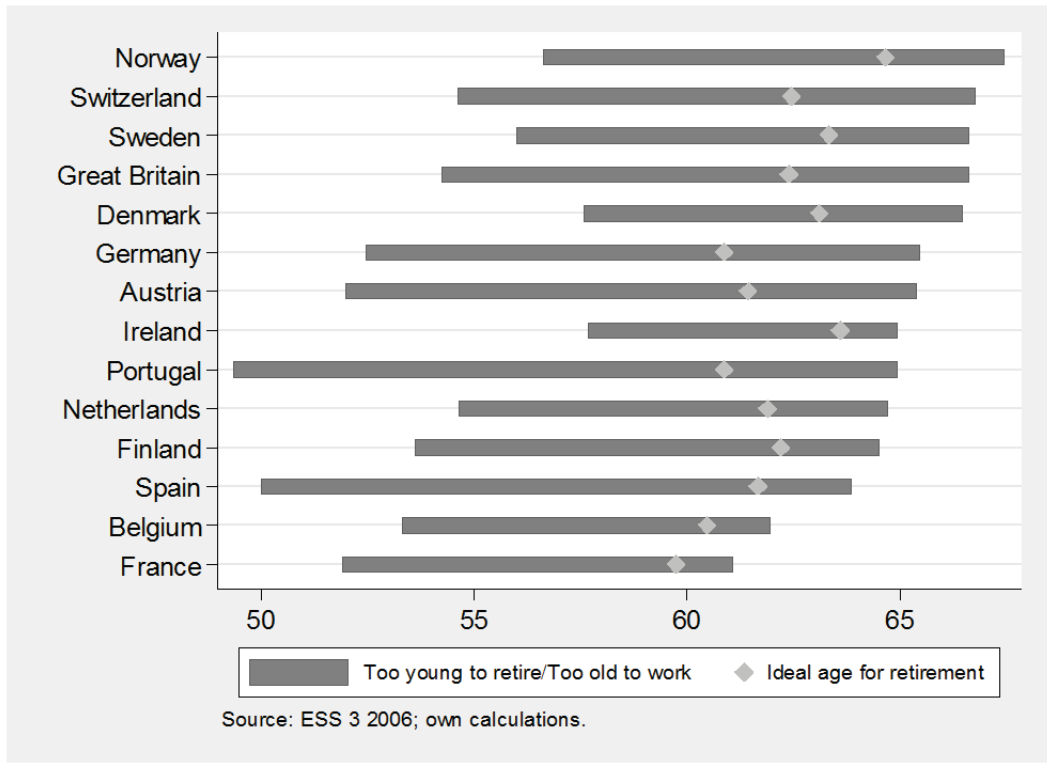

Fig 4.4 Mean Responses, Age Norms of Retirement by Country, Men.

to retire in the near future. This makes the variable particularly interesting for further investigation. This age deadline is also closely related to the debate on age discrimination at the workplace. By contrast, the norm on the youngest age seems less relevant, as few people can afford to retire this early anyway. Moreover, the adopted definition of retirement does not contemplate work withdrawal before age 50. It was already mentioned above that the behavioural relevance of the ideal age for retirement is doubtful. Besides, there is very little variation in this variable. Therefore it appears that the most socially pertinent age norms are captured by the perception of someone being too old to work. The following analyses will thus concentrate on the latest appropriate age for retirement.

\subsubsection{Age Cultures Across Europe}

Figure 4.4 shows mean values of the various retirement-norm items across countries. The bars show the range between the youngest and oldest age of retirement in the respective country, and the markers indicate the average ideal retirement age. In line with the age-culture hypothesis, the data reveal important country differences for male retirement norms. On the upper end of the scale, Norwegians on average said that a man is only too old to retire at over 67 years old; on the other extreme, the French think the same about men older than 61 years. 
It is easy to identify regional clusters in the country rankings. Not surprisingly, the Nordic countries are to be found in the upper section of the panel, although Finland curiously scores more than two years lower than its Scandinavian neighbors. Great Britain and Switzerland are characterised by a late-exit culture, while Ireland figures near the non-weighted country mean of 65 years. The mean response on the latest age for retirement is similarly at intermediate levels in Germany, Austria, and the Netherlands.

With their very low work attachment, France and Belgium stand in quite remarkable contrast to the other continental European countries. The picture of the Mediterranean countries generally reveals a high acceptance of early exit for men: Spanish respondents hold age norms that are consistently below average. Portugal shows the greatest age tolerance in this country comparison, scoring lowest on the youngest age for retirement but average on the oldest age. In this sense, we observe the most pointed age norms in Ireland, where the normatively defined age corridor for retirement stretches only over about seven years.

For women's retirement (figure 4.5), retirement age norms take lower values everywhere. Besides, inter-country variation is larger. France and Belgium again form a separate cluster, which is situated at more than two years below of any other country. According to Belgian respondents, a woman is too old to work after an age of 55 years. ${ }^{41}$ And for the average French respondent, a woman is not too young to retire at 48 years of age.

The Nordic countries clearly lead the country ranking, although the gender difference is also considerable here. Unlike for male retirement norms, Finnish respondents do not differ as much from their Scandinavian counter-parts with respect to latest age for leaving the labour market, although they are significantly more open to early retirement for women. For female retirement norms, Switzerland ranks only in the middle section of the European country ranking, exhibiting a similar profile to Germany. The Anglo-Saxon countries score about average, too.

Besides, it is remarkable that inhabitants of the Mediterranean countries commonly characterised as extremely gendered societies - do not seem to hold particularly discriminatory attitudes towards women's retirement. Instead, both Portugal and Spain rank somewhat higher than with respect to male retirement ages. The contrary is true for the Netherlands and Austria, where the gender gap seems to be particularly pronounced.

41 A somewhat odd pattern emerges for Belgium, as well as the Netherlands and Ireland: the mean age for a woman to be too old to work is lower than the respective mean ideal age of retirement. It is noticeable that this occurs only in countries with highly gendersegregated labour markets, but the reasons are unclear. 


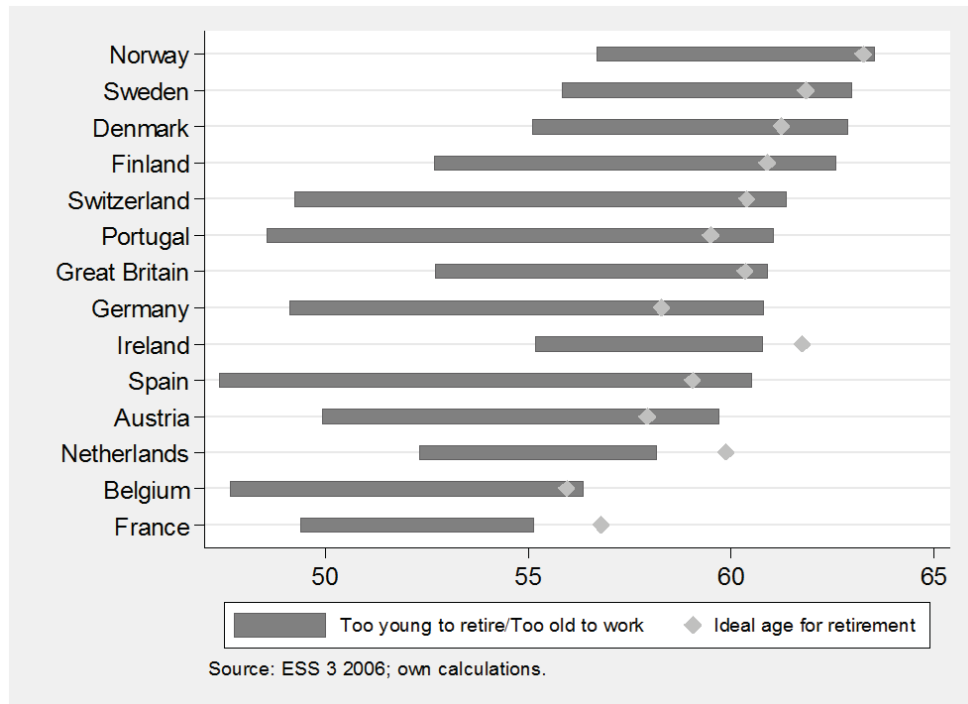

Fig 4.5 Mean Responses, Age Norms of Retirement by Country, Women.

Age norms for women's retirement are linked to the prevailing gender norms in society. Where traditionalist family values are still dominant, women's employment is seen critically in general, hence the low support for late retirement. Accordingly, a low score on these survey items may not only be driven by a high affinity for early retirement in general but also by gender norms. The greater cross-national variation for female retirement ages suggests that countries differ more with regard to gender norms than with regard to their retirement norms proper. Notably, France and Belgium - and not the Mediterranean countries - are the societies with the greatest gender disparities in retirement age norms.

\subsubsection{Age Norms, Gender, and Social Class}

On the micro level, we are primarily interested in two sources of variation: gender and social class (see sections 4.1 and 3.1.5). Fortunately, the data in hand allows for a twofold analysis along the gender dimension. Above, we already looked at the gender difference across the target sexes of retirement age norms (i.e. differences between the age norms targeted at men and women). The main finding was that age norms in European societies favor an earlier retirement for women.

Table 4.2 facilitates a more differentiated view, taking account of the sex of the respondent. The emerging picture is varied. On the question of whether a man or a woman counts as too young to retire, there are no significant differences between male and female respondents. Neither is this the case with regard to 
Table 4.2

Mean Response (weighted), Age Norms by Sex and Target Gender.

\begin{tabular}{|c|c|c|c|c|}
\hline SURVEY QUESTION & $\begin{array}{l}\text { RESPONDENTS' } \\
\text { SEX }\end{array}$ & $\begin{array}{l}\text { MEAN } \\
\text { IN YEARS }\end{array}$ & $\begin{array}{l}\text { STD. ERR. OF } \\
\text { THE MEAN }\end{array}$ & $\begin{array}{l}\text { SEX } \Delta \text { SIGNIFICANT } \\
\text { AT } 5 \% \text {-LEVEL }\end{array}$ \\
\hline \multicolumn{5}{|l|}{ a) } \\
\hline \multirow{3}{*}{$\begin{array}{l}\text { What is the ideal age } \\
\text { for a man to retire } \\
\text { permanently? }\end{array}$} & Total & 61.34 & .127 & \multirow[b]{3}{*}{ Yes } \\
\hline & Men & 60.88 & 190 & \\
\hline & Women & 61.79 & .149 & \\
\hline \multirow{3}{*}{$\begin{array}{l}\text { What is the ideal age } \\
\text { for a woman to retire } \\
\text { permanently? }\end{array}$} & Total & 58.78 & .128 & \multirow[b]{3}{*}{ No } \\
\hline & Men & 58.59 & . 198 & \\
\hline & Women & 58.96 & .171 & \\
\hline \multicolumn{5}{|l|}{ b) } \\
\hline \multirow{3}{*}{$\begin{array}{l}\text { Before what age is } \\
\text { a man too young to } \\
\text { retire? }\end{array}$} & Total & 52.80 & .174 & \multirow[b]{3}{*}{ No } \\
\hline & Men & 52.90 & .260 & \\
\hline & Women & 52.70 & .234 & \\
\hline \multirow{3}{*}{$\begin{array}{l}\text { Before what age is a } \\
\text { woman too young to } \\
\text { retire? }\end{array}$} & Total & 50.02 & .240 & \multirow[b]{3}{*}{ No } \\
\hline & Men & 50.12 & .310 & \\
\hline & Women & 49.92 & .319 & \\
\hline \multicolumn{5}{|l|}{ c) } \\
\hline \multirow{3}{*}{$\begin{array}{l}\text { After what age is a } \\
\text { man too old to work? }\end{array}$} & Total & 64.58 & .132 & \multirow{3}{*}{ No } \\
\hline & Men & 64.19 & .209 & \\
\hline & Women & 64.96 & .180 & \\
\hline \multirow{3}{*}{$\begin{array}{l}\text { After what age is a } \\
\text { woman too old to } \\
\text { work? }\end{array}$} & Total & 59.86 & .147 & \multirow[b]{3}{*}{ Yes } \\
\hline & Men & 59.35 & .213 & \\
\hline & Women & 60.34 & .209 & \\
\hline
\end{tabular}

Source: ESS 3.2; author's calculations.

the ideal retirement age for a woman or the oldest retirement age for a man. That is, men and women largely agree on these issues, and crucially, neither of the two sexes has more gender-egalitarian attitudes. Since women are accordingly supposed to exit the labour force earlier than men, the gendered age-norm hypothesis $(\mathrm{H} 3 \mathrm{a}$ ) finds clear support.

The data also show that male and female respondents held significantly different opinions on certain issues. This is the case for the age after which a woman is too old to work, as well as for the ideal age for retirement for men. According to women, women become too old to retire at a later age than the age at which men think women are too old to retire. Notably, this is exactly the opposite pattern to the one posited by the preference-theory hypothesis ( $\mathrm{H} 3 \mathrm{~b}$ ). However, the other two questions regarding women do not reveal significant differences in opinion according to the sex of the respondent. At the same 


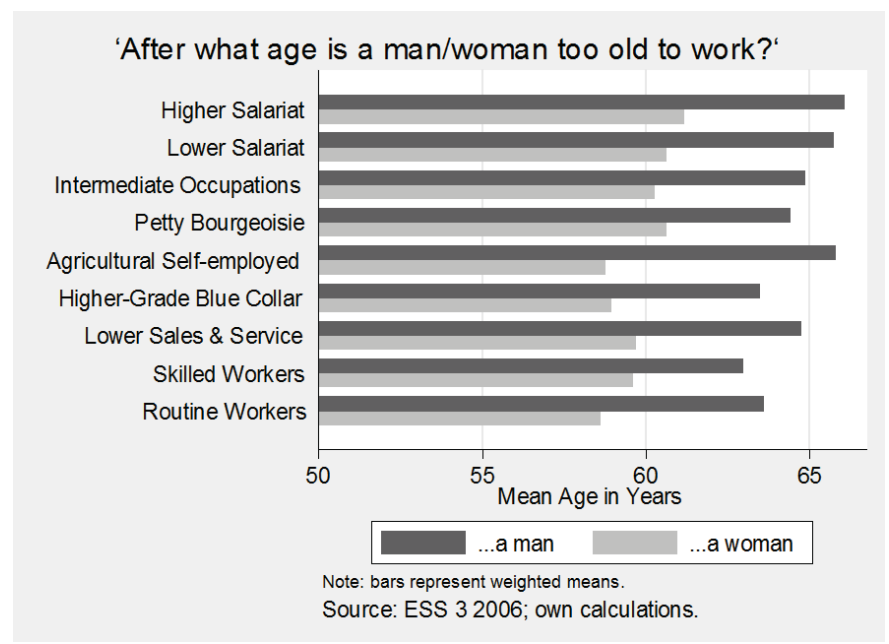

Fig. 4.6 Age After Which a Man/Woman is Too Old to Work, by Class.

time, women regard a slightly higher age as optimal for men to retire than men themselves. The gender gap for the oldest retirement age for men is at the edge of being significant, at the $5 \%$ level.

In sum, it appears on the basis of these descriptive statistics that most women have internalised social norms prescribing gender-differential labour market participation as much as men. The evidence does not support the view that men have the more gender-discriminatory opinions, or that men and women have antagonistic world views. Gender differences are more subtle. On the one hand, women give themselves more time before they consider themselves too old for work than men give them. On the other hand, women consider the ideal retirement age of men to be higher than men themselves consider it to be.

Figure 4.6 shows mean responses on the oldest appropriate age for retirement by social class and gender. It makes palpable the pronounced class differences in age norms. The maximal class differential is more than three years. Moreover, it shows that social class is also an intervening variable in the gender-attitudes relation, although a lower retirement age for women is found appropriate among all classes.

By and large, the specificity of skills is positively related to a norm of late exit. In detail, the higher and lower salariat, as well as farmers, are most supportive of a long working life for men. Somewhat surprisingly, the petty bourgeoisie scores lower, despite the fact that the self-employed are generally associated with a high work attachment. Skilled workers have the lowest affinity to late retirement, even lower than their semi- and unskilled colleagues. Those in intermediate occupations, as well as low-skilled service employees, exhibit average attitudes towards late exit for men. 
The gender gap is considerable among members of all classes. This consensus on gender-specific retirement norms is a telling piece of evidence. Within these limits, the gender gap is nevertheless contingent on class membership to some degree. With farmers, we find the greatest gender disparity: while placing the latest age for retirement for men at age 65 , for women, they situate it at only 58 years. By contrast, for skilled workers, the gender differential is much smaller, as norms on men's and women's retirement converge at a low level. Notably, the perceived difference between male and female retirement is also small among the petty bourgeoisie. Otherwise, the class-graded pattern of female age norms is close to the pattern of male age norms.

As set out in section 3.1.2, the fact that age norms vary to some extent according to social groups lines up with the conception of age norms as local norms (Bicchieri 2006). The gendered pattern of responses is a manifestation of precisely this specificity of age norms for different target groups. Admittedly, though, one shortcoming of the preceding analyses is that other population characteristics and target group characteristics are inevitably confounded. In the case of the social-class differences examined here, the analyst cannot know with certainty to what degree people's own disposition enters into their survey responses. This caveat, which also applies to the following regression results, refers back to the difference between internalised social norms and work orientations (cf. section 3.1.5). Put another way, given the data in hand, it is impossible to ascertain how much respondents give their opinion of the "generalised other" and how much they evaluate their own situation. The measured impact of socio-economic characteristics on age norms (other than gender) can correspondingly be interpreted in two different ways: either we deal with differences in social norms for distinct target groups or we pick up patterns of heterogeneous work orientations.

\subsection{Determinants of Retirement Age Norms at the Micro Level}

\subsubsection{Modelling Strategy}

In the following, the determinants of retirement norms and preferences will be assessed in a censored regression framework. The analysis deals with social norms concerning the oldest age of retirement, which have been identified as the most relevant of the variables available in the ESS. The estimations are carried out for age norms targeted at men and women separately.

In order to scrutinise the influence of social class, three different model specifications will be presented for two different sample populations 
respectively: the first model for the full sample includes the main variables of interest - sex of the respondent and social class - alongside most control variables, including country dummies; in an attempt to cope with the potential endogeneity of employment status, the set of employment-status dummies is entered into the regression equation in a second step. To scrutinise the effect of social class, the covariates income, years of education, trade union membership, and health status are introduced separately.

A second set of models is presented for the subsample of employed respondents only, as it can be expected that the determinants of retirement preferences are not the same for working persons as for those outside the labour market. After starting again with a parsimonious model, the job-related variables, such as income and education, are entered. Focusing only on employed respondents allows the inclusion of variables related to work satisfaction and the quality of the job in the final model specification.

\subsubsection{Empirical Estimation Results}

Table 4.3 displays the results from the multivariate two-limit tobit regression model concerning the age-appropriate retirement behavior of men. Interestingly, female respondents turn out to hold retirement age norms targeted at men that are significantly higher than those of their male counterparts. When controlling for their other socio-economic characteristics, women situate the moment when a man becomes too old to work about nine months later (on the latent underlying variable) than men themselves. This result goes beyond the descriptive findings above, where the sex differential for the variable in question was only at the border of significance.

The estimations substantiate that social class affects retirement norms. Members of the service class are significantly more supportive of late retirement for men than routine workers. The marginal effect is quite sizeable. Besides, the two classes of self-employed and small employers appear to hold similar attitudes. The finding of an influential class effect corroborates the above results based on the bivariate association.

In the second model, the newly entered employment status variable in fact turns out to be correlated with retirement preferences. Overall, the nonemployed are more supportive of early retirement than the employed. The negative effect is strong among the unemployed, who remain at 1.5 years below the working population with respect to their support for late exit; retirees are equally in favor of men retiring early. These findings are in line with a revealed preference perspective, yet they cannot be interpreted causally, as selection effects are likely to be at work (cf. section 4.4.2). 
Tobit Model, Age After Which A Man Is Too Old to Work, Micro.

\begin{tabular}{|c|c|c|c|c|c|c|}
\hline & \multicolumn{3}{|c|}{ ALL RESPONDENTS BORN 1930-57 } & \multicolumn{3}{|c|}{ ONLY EMPLOYED RESPONDENTS } \\
\hline & 1 & 2 & 3 & 4 & 5 & 6 \\
\hline Female & $.826^{\ldots \ldots * 0}$ & $.724^{* \ldots *}$ & $.653 \cdots$ & $.832^{* * x}$ & .769 & $.789 * *$ \\
\hline Age & .439 & .607 & .575 & -1.446 & -1.391 & -1.357 \\
\hline Age squared & -.003 & -.004 & -.003 & .013 & .013 & .013 \\
\hline \multicolumn{7}{|c|}{$\begin{array}{l}\text { Social Class (ESeC) } \\
\text { (Reference: Routine Workers) }\end{array}$} \\
\hline Higher Salariat & $1.673 \ldots$ & 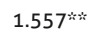 & $1.118^{\cdots \cdots}$ & $2.185^{* * *}$ & $1.780^{* * *}$ & $1.789 *$ \\
\hline Lower Salariat & $1.652 \ldots$ & $1.655^{* \ldots}$ & $1.352^{\ldots * m}$ & $1.800 \ldots$ & $1.615^{\ldots \ldots * k}$ & $1.635 \%$ \\
\hline $\begin{array}{l}\text { Intermediate } \\
\text { Occupations }\end{array}$ & .462 & .442 & .214 & .242 & .196 & .222 \\
\hline Petite Bourgeoisie & $.829 *$ & .674 & .379 & .101 & -.186 & -.172 \\
\hline $\begin{array}{l}\text { Agricultural Self- } \\
\text { employed }\end{array}$ & $1.810^{*}$ & 1.654 & 1.379 & 1.130 & .999 & 1.023 \\
\hline $\begin{array}{l}\text { Higher-Grade Blue- } \\
\text { Collar }\end{array}$ & -.233 & -.151 & -.172 & -1.100 & -1.067 & -1.044 \\
\hline $\begin{array}{l}\text { Lower Sales \& } \\
\text { Service }\end{array}$ & -.156 & -.107 & -.237 & .627 & .490 & .466 \\
\hline Skilled Manual & -.439 & -.322 & -.352 & -2.227 & $-2.277^{* x}$ & -2.227 \\
\hline \multicolumn{7}{|c|}{$\begin{array}{l}\text { Employment Status } \\
\text { (Reference: Employed) }\end{array}$} \\
\hline Retired & - & $-1.519 \ldots$ & $-1.236 \%$ & - & - & - \\
\hline Unemployed & - & $-1.512 \ldots$ & $-1.215^{*}$ & - & - & - \\
\hline Homemaker & - & -.200 & -.128 & - & - & - \\
\hline Years of Education & - & - & .027 & - & .022 & .024 \\
\hline Log HH-Income & - & - & .409 & - & .331 & .335 \\
\hline $\begin{array}{l}\text { Trade Union } \\
\text { Member }\end{array}$ & - & - & $-1.092^{\ldots+k t}$ & - & -1.366 & -1.388 \\
\hline $\begin{array}{l}\text { Health less than } \\
\text { good }\end{array}$ & - & - & -.805 & - & -.648 & -.637 \\
\hline Job satisfactory & - & - & - & - & - & -.026 \\
\hline Job interesting & - & - & - & - & - & .089 \\
\hline Job stressful & - & - & - & - & - & -.425 \\
\hline $\begin{array}{l}\text { Job stressful } \\
\text { squared }\end{array}$ & - & - & - & - & - & .061 \\
\hline \multicolumn{7}{|c|}{$\begin{array}{l}\text { Family Situation } \\
\text { (Reference: Married, Spouse employed) }\end{array}$} \\
\hline $\begin{array}{l}\text { Married, Spouse } \\
\text { retired }\end{array}$ & $-.872 \ldots$ & $-.549 *$ & $-.532 \ldots$ & $-1.593 \ldots$ & $-1.639 \%$ & -1.685 \\
\hline
\end{tabular}


Table 4.3

Tobit Model, Age After Which A Man Is Too Old to Work, Micro.

\begin{tabular}{|c|c|c|c|c|c|c|}
\hline & \multicolumn{3}{|c|}{ ALL RESPONDENTS BORN 1930-57 } & \multicolumn{3}{|c|}{ ONLY EMPLOYED RESPONDENTS } \\
\hline & 1 & 2 & 3 & 4 & 5 & 6 \\
\hline $\begin{array}{l}\text { Married, Spouse } \\
\text { inactive }\end{array}$ & -.503 & -.300 & -.198 & $-1.063 *$ & -.970 & -.954 \\
\hline Divorced & .074 & .337 & 612 & .226 & .364 & .335 \\
\hline Never married & -.353 & -.058 & .240 & $2.071^{2}$ & $2.279 \ldots$ & $2.251^{* * *}$ \\
\hline Widowed & -1.138 & -.919 & -.732 & -.982 & -.976 & -.926 \\
\hline $\begin{array}{l}\text { No. of } \\
\text { grandchildren }\end{array}$ & -.142 & -.138 & -.119 & -.151 & -.115 & -.120 \\
\hline $\begin{array}{l}\text { Mother working } \\
\text { (age 16) }\end{array}$ & .294 & .298 & .353 & $.947^{*}$ & $.995 \%$ & $1.002 *$ \\
\hline \multicolumn{7}{|c|}{$\begin{array}{l}\text { Father's Education } \\
\text { (Reference: Less than primary) }\end{array}$} \\
\hline Primary & .209 & .197 & .103 & -.107 & -.183 & -.186 \\
\hline Lower secondary & .918 & .858 & .747 & -.648 & -.743 & -.753 \\
\hline Upper secondary & .819 & .772 & .599 & -.399 & -.521 & -.549 \\
\hline Teritary & .960 & .883 & .658 & -.003 & -.191 & -.168 \\
\hline \multicolumn{7}{|c|}{$\begin{array}{l}\text { Country } \\
\text { (Reference: Germany) }\end{array}$} \\
\hline Sweden & $2.946 \ldots$ & $2.673^{\cdots}$ & $2.855^{\prime \prime \prime \prime}$ & $2.243^{\prime \prime m}$ & $2.481 \ldots$ & 2.478 \\
\hline Denmark & $3.997^{*}$ & $3.940 \ldots$ & $4.139 \%$ & $4.316 \ldots$ & $4.620 \cdots$ & $4.633^{\cdots}$ \\
\hline Spain & -1.250 & -1.572 & $-1.654^{* \ldots k n}$ & -2.382 & $-2.525^{* \ldots * m}$ & -2.614 \\
\hline Belgium & $-3.887 \ldots$ & $-3.895 \%$ & $-3.891 * \ldots$ & $-3.087 \ldots$ & $-3.188 \cdots$ & $-3.233 \ldots$ \\
\hline France & $-5.432 \ldots$ & $-5.433^{*}$ & $-5.612^{\prime}$ & -5.260 & $-5.501 \%$ & $-5.533 \ldots$ \\
\hline Switzerland & $2.716 \ldots$ & $2.526 \ldots$ & 1.819 & $1.693 \ldots$ & $1.017^{*}$ & $1.018^{*}$ \\
\hline Finland & -.147 & -.133 & .142 & -.857 & -.515 & -.484 \\
\hline Great Britain & $2.368^{\ldots}$ & $2.337 \ldots$ & 2.262 & 2.559 & $2.502 \ldots$ & $2.487^{\cdots \cdots}$ \\
\hline Norway & $1.643^{\cdots}$ & $1.449 \ldots$ & $1.387^{\cdots * k}$ & $1.689 \ldots$ & $1.708 \ldots$ & $1.727^{\cdots \cdots}$ \\
\hline Portugal & -.081 & -.161 & .114 & -.274 & -.258 & -.276 \\
\hline Ireland & $3.992 \ldots$ & 3.806 & $3.574^{* \ldots * \ldots}$ & $3.384 \ldots$ & $3.177^{\ldots \ldots k}$ & 3.133 \\
\hline Netherlands & .145 & .013 & -.284 & -.710 & -1.074 & $-1.162 *$ \\
\hline Austria & $.739 *$ & $.702 *$ & .583 & -.374 & -.457 & -.419 \\
\hline Constant & $49.542^{\ldots}$ & 43.689 & 42.189 & 105.236 & 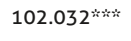 & $101.413^{\ldots}$ \\
\hline $\begin{array}{l}\text { McKelvey \& } \\
\text { Zavoina's R² }\end{array}$ & .506 & .515 & .523 & .551 & .557 & .557 \\
\hline $\mathrm{N}$ & 5231 & 5231 & 5231 & 2069 & 2069 & 2069 \\
\hline
\end{tabular}

Source: ESS 32006

* $p<0.1$, * $p<0.05$, * $p<0.01$ 
Class effects are hardly affected at all by the inclusion of employment status. It is confirmed that the higher and lower salariat have a much higher work attachment at the end of working life than unskilled workers. The magnitude of the effect amounts to about 20 months. It is worth noting that the attitudinal difference between the salariat and working class also remains significant after the inclusion of other job-related characteristics in the full models 3 and 6 . There are no appreciable differences with respect to retirement age norms for men between the remainder of the class categories, however. That is, among the bulk of lower- and middle-class dependently employed, ranging from unskilled blue-collar workers and lower sales and service personnel to lower technicians and intermediate service occupations, we find no further internal differentiation in terms of attitudes towards men's retirement.

Among the job-related variables entered in the third model, only being a member of a trade union accounts for a significant difference in age norms concerning men's exit from work. Concretely, trade union members rate at one year below non-union members. The coefficient corresponding to years of education yields the expected positive association, but it is no significant predictor of retirement attitudes beyond class membership.

Likewise, neither household income nor health status at the time of the interview seems to matter. In terms of the social mechanisms behind class effects, it can be concluded that the specific occupational work experience as well as peer-group and selection effects likely account for the lion's share of the class effect in retirement attitudes.

Besides, the household context exerts a non-trivial influence on retirement attitudes. We observe the predicted "joint lunches" effect, i.e. a low commitment to late exit among people whose spouse is retired. By contrast, the socioeconomic situation of the family of origin does not play a major role, and the presence of grandchildren is not noticeable in retirement attitudes either.

The second set of regressions exclusively analyses the retirement age norms of employed respondents. This yields some additional insights. The initially observed differences between the service class and unskilled workers are larger among the economically active than within the full sample. Further, skilled manual workers display an even greater propensity to retire early than unskilled manual workers. The former situate themselves at more than two years below the latter. Again, the inclusion of other job-related characteristics in model five does not much alter this pattern of class regularities.

Another interesting deviation from the full sample (comprising all respondents aged 50 or more) takes place at the household level. Specifically, the "joint lunches" effect, the increased preference for early exit among married persons with a retired spouse, is amplified. Accordingly, the linked-lives effect is of far greater magnitude for the employed than for the inactive population. More, married people with an inactive spouse seem to share a similar attitude. 
For those who never married, interestingly, men only become too old to work two years later than in the views of married people with a working spouse.

The last column of table 4.3 shows the results from a model that includes a series of job quality variables. Yet, all turn out not to be statistically significant. Given the strength of class effects, this is a puzzling result that stands in opposition to the argument that classes differ in their retirement preferences in part because of diverse working conditions. Upon closer observation, however, it turns out that class differentials on the three job-quality variables are actually very small. This ambiguity is broadly in line with previous research, which found inconclusive class differences in job satisfaction (Svallfors 2006). It can be argued that this is due to the adaption of expectations (Grint 2005). Satisfaction with work does not depend solely on the objective quality of work but also on subjective expectations and the reference group for intersubjective comparisons (Svallfors 2006: 42). In spite of having a less interesting job, workers may not have a negative perception of their work if they do not expect anything more from their employment (cf. Grint 2005). Albeit not being captured by job satisfaction measures, differences in work conditions can still have an unobservable effect on retirement preferences. In any case, the concept of social class involves more than working conditions (cf. section 3.3.2).

The regression results regarding attitudes towards women's retirement, shown in table 4.4, differ in some respects. Particularly for social class, the effects are markedly stronger. The difference to routine workers is much larger now for the upper and lower salariat as well as for the petty bourgeoisie. For instance, large employers and professionals think that women become too old to work more than three years later than unskilled workers. Moreover, we now find statistically important effects also for intermediate occupations and higher-grade bluecollar workers, that is, for the two classes with a mixed employment relationship.

Again, the class effects on age norms hardly change when controlling for employment status. And as with norms for men, the diagnosed class effects for women are only to a small extent attributable to education, income, or trade union membership. There is only a weakly significant income effect, which is positive and explains some part of the difference between the service and the working classes. In line with expectations, poor health translates into a more favorable opinion of early exit for women.

The sex of the respondent is also a significant determinant of age norms concerning women's retirement. Given the general normative consensus on gendered retirement patterns revealed above, the greater prevalence of lateexit norms among women is a striking finding. While at face value the difference between men and women was one year (see 4.5.3), the effect under ceteris paribus conditions is between one-and-a-half to two years. In other words, the fact that women give themselves more time before getting too old to work than men give women is even more remarkable given their socio-economic profile, 
Tobit Model, Age After Which A Woman Is Too Old to Work, Micro.

\begin{tabular}{|c|c|c|c|c|c|c|}
\hline & \multicolumn{3}{|c|}{ ALL RESPONDENTS BORN 1930-57 } & \multicolumn{3}{|c|}{ ONLY EMPLOYED RESPONDENTS } \\
\hline & 1 & 2 & 3 & 4 & 5 & 6 \\
\hline Female & $1.504^{m+x}$ & $1.782 \ldots$ & 1.986 & $2.082 \ldots$ & 2.241 & 2.326 \\
\hline Age & .435 & $.622 *$ & $.548 *$ & .178 & .250 & .260 \\
\hline Age squared & -.003 & $-.004^{*}$ & -.004 & -.000 & -.001 & -.001 \\
\hline \multicolumn{7}{|l|}{$\begin{array}{l}\text { Social Class (ESeC) } \\
\text { (Reference: Routine Workers) }\end{array}$} \\
\hline Higher Salariat & $3.318 * *$ & $3.295 \% *$ & $2.045^{* \ldots t}$ & $2.657^{* \ldots x}$ & 1.724 & 1.786 \\
\hline Lower Salariat & $2.927 \cdots$ & $2.856 \ldots$ & $1.923 \cdots$ & $2.846 \cdots$ & $2.176 \%$ & $2.311^{* * \mathrm{k}}$ \\
\hline Intermediate Occupations & $1.526^{*}$ & $1.534 *$ & .876 & 619 & .282 & .231 \\
\hline Petite Bourgeoisie & $3.945^{\cdots * *}$ & $3.785 \%$ & $3.421 \ldots$ & $3.518 \cdots$ & $3.365 *$ & $3.164 \ldots$ \\
\hline $\begin{array}{l}\text { Agricultural Self- } \\
\text { employed }\end{array}$ & .959 & .705 & .630 & -1.311 & -1.273 & -.912 \\
\hline Higher-Grade Blue-Collar & $1.635^{\ldots * *}$ & $1.601 \%$ & $1.229 *$ & 1.156 & 1.028 & 1.048 \\
\hline Lower Sales \& Service & .970 & .978 & .713 & .862 & .883 & .922 \\
\hline Lower Technical & .766 & .840 & .904 & 1.058 & 1.279 & 1.113 \\
\hline \multicolumn{7}{|l|}{$\begin{array}{l}\text { Employment Status } \\
\text { (Reference: Employed) }\end{array}$} \\
\hline Retired & - & $-1.223 \%$ & -.793 & - & - & - \\
\hline Unemployed & - & .963 & $1.590 *$ & - & - & - \\
\hline Homemaker & - & -2.028 & -1.512 & - & - & - \\
\hline Years of Education & - & - & .133 & - & .095 & .087 \\
\hline Log HH-Income & - & - & $.687^{*}$ & - & .578 & .535 \\
\hline Trade Union Member & - & - & .192 & - & .270 & .334 \\
\hline Health less than good & - & - & 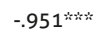 & - & -1.201 & -.947 \\
\hline Job satisfactory & - & - & - & - & - & .191 \\
\hline Job interesting & - & - & - & - & - & .108 \\
\hline Job stressful & - & - & - & - & - & -.074 \\
\hline Job stressful squared & - & - & - & - & - & -.063 \\
\hline \multicolumn{7}{|c|}{$\begin{array}{l}\text { Family Situation } \\
\text { (Reference: Married, Spouse employed) }\end{array}$} \\
\hline Married, Spouse retired & $-1.640 \ldots$ & $-1.492 \ldots$ & $-1.390 \ldots$ & $-1.737 \ldots$ & $-1.646 *$ & $-1.755 \%$ \\
\hline Married, Spouse inactive & -1.234 & -1.182 & -.859 & $-1.840 *$ & $-1.581^{*}$ & -1.523 \\
\hline Divorced & -.635 & -.715 & -.250 & -.308 & .007 & .014 \\
\hline
\end{tabular}


Table 4.4

Tobit Model, Age After Which A Woman Is Too Old to Work, Micro.

\begin{tabular}{|c|c|c|c|c|c|c|}
\hline & \multicolumn{3}{|c|}{ ALL RESPONDENTS BORN 1930-57 } & \multicolumn{3}{|c|}{ ONLY EMPLOYED RESPONDENTS } \\
\hline & 1 & 2 & 3 & 4 & 5 & 6 \\
\hline Never married & -.710 & -.679 & -.273 & -1.565 & -1.294 & -1.327 \\
\hline Widowed & $-1.466 \%$ & $-1.410 \%$ & -.910 & $-2.347^{\cdots * k}$ & $-1.936 *$ & $-1.950 *$ \\
\hline No. of grandchildren & -.108 & -.101 & -.078 & .024 & .062 & .053 \\
\hline Mother working (age 16) & .160 & .168 & .201 & .387 & .382 & .391 \\
\hline \multicolumn{7}{|c|}{$\begin{array}{l}\text { Father's Education } \\
\text { (Reference: Less than primary) }\end{array}$} \\
\hline Primary & .526 & .513 & .193 & .401 & .148 & .116 \\
\hline Lower secondary & $1.244 \%$ & $1.175^{\ldots *:}$ & .838 & $2.105 \%$ & $1.905^{\ldots * n}$ & $2.004 \%$ \\
\hline Upper secondary & $1.491^{*}$ & $1.418 \ldots$ & .727 & $2.164 \%$ & 1.562 & 1.624 \\
\hline Tertiary & $2.316 \ldots$ & $2.226 \ldots$ & $1.388 *$ & $2.996 \ldots$ & $2.393^{* *: *}$ & $2.653 \%$ \\
\hline \multicolumn{7}{|l|}{$\begin{array}{l}\text { Country } \\
\text { (Reference: Germany) }\end{array}$} \\
\hline Sweden & $3.593 \ldots$ & $3.305^{\mathrm{m}}$ & 2.839 & 4.156 & 3.569 & 3.644 \\
\hline Denmark & $4.852 \%$ & $4.673 \ldots$ & 4.193 & $4.944 \%$ & 4.309 & $3.842 \ldots$ \\
\hline Spain & -.042 & .132 & .288 & .285 & .202 & -.067 \\
\hline Belgium & -6.227 & -6.164 & -6.422 & -4.793 & -5.158 & -5.229 \\
\hline France & $-6.214 *$ & $-6.205^{*}$ & -6.309 & $-5.705^{*}$ & $-5.772 \ldots$ & -5.627 的 \\
\hline Switzerland & $2.907^{* \ldots k n}$ & $2.934 \%$ & $2.269 \%$ & $3.748 \ldots$ & $3.066 \ldots$ & $3.213 \ldots$ \\
\hline Finland & $3.739 \%$ & $3.530 \%$ & $3.140 \%$ & $3.800 \%$ & $3.289 \%$ & $3.467 \%$ \\
\hline Great Britain & 2.345 & $2.244^{\prime \prime m}$ & 1.812 & $3.064 \%$ & $2.509 \%$ & 2.517 \\
\hline Norway & $1.674^{*}$ & $1.518 \ldots$ & .765 & $1.379 \%$ & .546 & .276 \\
\hline Portugal & 1.008* & $.968 *$ & 2.047 & $1.793 \%$ & $2.569 \%$ & 2.380 \\
\hline Ireland & $4.734 \%$ & 4.879 & $4.243 \ldots$ & $4.287^{\ldots}$ & $3.793 \ldots$ & $3.480 \cdots$ \\
\hline Netherlands & $-1.314^{* \ldots x}$ & $-1.227^{* \ldots * m}$ & 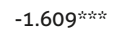 & .139 & -.298 & -.822 \\
\hline Austria & -.177 & -.140 & -.384 & .939 & .608 & .481 \\
\hline Constant & 46.338 & $39.657^{2}$ & $35.531^{*}$ & 50425 & 43076 & 43133 \\
\hline McKelvey \& Zavoina's R² & .483 & .491 & .497 & .521 & .523 & .538 \\
\hline $\mathrm{N}$ & 5361 & 5361 & 5361 & 2145 & 2145 & 2145 \\
\hline
\end{tabular}

Source: ESS 32006

* $p<0.1$, ** $p<0.05$, *** $p<0.01$ 
which would generally suggest a greater approval of early exit from work. The sex-based difference is much greater than for norms directed at men's retirement. Based on this evidence we reject the preference-theory hypothesis ( $\mathrm{H} 3 \mathrm{~b})$.

Additional information on the gender nexus is conveyed by the coefficients corresponding to family situation and employment status in the second model. It turns out that homemakers - who are predominantly female - express an extremely low approval of late exit among women. Respondents with a retired spouse - and the majority of those were in this instance female - hold age norms that are particularly in favor of early exit of women from the labour market. Together, these findings thus point to a considerable degree of heterogeneity among women concerning their retirement preferences. Nevertheless, the findings displayed contradict the suggestion by Hakim that the majority of women - the adaptive group in her typology - do not have strong work attachment.

A father's level of education significantly impacts attitudes towards women's retirement. The pattern is linear and positive. Evidently, the family of origin plays an important role for gender norms, even among people aged 50 or older. Children of fathers with higher education think that women become too old to work more than two years later than children whose father has less than primary education (some 18\% of the respondents in the analysis sample). Given the high degree of social immobility in Western European societies (Erikson \& Goldthorpe 1992) and the strong class effects found in the present analysis, it is evident that family origin exerts a very strong effect on respondents' views regarding retirement. Against prior expectations, the earlier labour market activity of the respondents' mothers has no effect.

The results from the second set of models for employed persons do not diverge much from the full sample. Unlike for male retirement norms, class effects for female retirement norms are now slightly weaker among the working population. It could be speculated that this reflects a cohort effect in gender norms that tend to become more egalitarian across all social classes. For men, the "joint lunches" effect, regarding the presence of a retired spouse, is more salient among employed than among non-employed respondents. The reason behind the negative effect for widowed respondents is not obvious.

In contrast to previous studies (Neugarten et al. 1965; Esser 2005b), age seems not to be particularly relevant for either male or female retirement norms. This divergence from earlier findings probably owes itself to this study's looking exclusively at the 50-plus population. Among those in the second half of their lives, age is not a main driving force of retirement attitudes. Unfortunately, the cross-sectional nature of the data set does not allow for a distinction between age and cohort effects.

Overall, although the findings from the bivariate analysis concerning social class are largely confirmed for men, multivariate regression pinpoints an even more important role of class regarding work exit norms for females. 
Class membership not only affects work orientations but also gender norms. ${ }^{42}$ Therefore, the classed-age-norms hypothesis is supported. In contradiction to the individualisation hypothesis, social-class membership proves to be important in shaping retirement age norms, most clearly along the broad distinction of service class versus working class.

The country coefficients in tables 4.3 and 4.4 roughly correspond to the descriptive findings discussed in section 4.5.2. In light of significant country effects, often of large magnitude, the age-culture hypothesis is again underpinned in the multivariate framework. Considering the particular effects, the results by and large confirm the conclusions from the descriptive analysis above. The next section analyses cross-national variation in age norms in detail.

\subsection{Determinants of Age Cultures at the Macro Level}

\subsubsection{Modelling Strategy}

In this section, the macro determinants of age cultures are assessed more closely. Since a dynamic approach would require longitudinal data, countrylevel institutions are here assumed exogenous.

The preceding analyses have been conducted for a sample composed of the birth cohorts 1930 to 1957 . Unfortunately, reliable indicators about the monetary early retirement incentives for a large number of pension systems are only available for men. The best pension-wealth measure to date is provided by Whitehouse (2006) (see section 4.4 .4 above). It is problematic to apply this central indicator to the older cohorts in the sample, however, because it only reflects the legal situation around 2004. For example, the oldest persons in the main sample are born in 1930, and consequently turned 60 in 1990. But given that there have been reforms of the pension system for early exit in many countries since the 1990s, these retirees often faced different financial conditions in their retirement decision than those born later. Therefore, I decided to exclude the oldest respondents from the sample used for the macro-level

42 Because of space limitations, no interaction effects of class and gender are presented. In further analyses not shown here, it turned out that the only class effect that was crucially mediated through the sex of the respondent relates to farmers. While farmers did not differ significantly from routine workers in their opinions on the age at which women become too young to retire, the marginal effect was as large as four years among female farmers only. Curiously, a similar pattern could be found among male farmers and their opinion on the retirement of men. It appears that both male and female farmers would like to work longer than their spouses find appropriate. 
models. In detail, the following analyses are restricted to those respondents born later than December 1939, that is, those born from 1940 to 1957.43

While estimating the impact of macro-level factors, all micro-level variables discussed above are simultaneously controlled for. Results are readjusted to give each country equal weight. By cancelling out compositional effects, this procedure facilitates an assessment of the leverage of institutional and structural factors at the country level. As before, the analysis proceeds in various steps in order to gain an impression of the possible causal mechanisms involved.

The discussion of macro-level results starts by evaluating the impact of pension-system generosity on age cultures. The first model specification introduces the OECD pension-wealth measures that capture the early retirement incentives inherent in European public pension schemes. Next, the early and normal-retirement age boundaries are introduced to the model. The third specification adds the unemployment rate in each country among senior workers, aged 50 to 64 years, in order to assess the importance of labour market conditions. Finally, the fourth model taps into the question of interdependent age cultures and retirement behaviour by introducing the mean retirement age at the time respondents turned 50. To this purpose, the variables referring to individual age have to be dropped from the last specification.

\subsubsection{Empirical Estimation Results}

Table 4.5 shows the estimated effects of the macro factors from the tobit censored regression model. The models in the first column test how far pensionwealth measures alone capture the observed cross-country variation in age norms. It turns out that the variable containing the change in pension wealth due to postponement of retirement from age 60 to 65 returns the hypothesised positive sign, but this effect is not significantly different from zero. For the average level of pension wealth at age 60 , in turn, we expected a negative relationship. Again, the empirical evidence supports the direction of the effect, which, however, stays below conventional levels of statistical significance for both sample populations. As for the preference-regulation hypothesis, if individuals form their preferences as a function of their opportunity structure, the effect is not strong enough to pass the t-test.

As a next step, I introduce the normal and minimum age of retirement. The results indicate that the higher the official retirement age of a pension system,

43 Robustness checks have been conducted to verify that this sub-sample responds to the same micro-level regularities as the full sample. Deviations are negligible. 
Table 4.5

Tobit Model, Age After Which a Man Is Too Old to Work, Macro.

\begin{tabular}{|c|c|c|c|c|}
\hline & $\begin{array}{c}\text { Model } \\
1\end{array}$ & $\begin{array}{c}\text { Model } \\
2\end{array}$ & $\begin{array}{l}\text { Model } \\
\quad 3\end{array}$ & $\begin{array}{c}\text { Model } \\
4\end{array}$ \\
\hline \multicolumn{5}{|l|}{ A) } \\
\hline \multicolumn{5}{|l|}{$\begin{array}{l}\text { ALL RESPONDENTS } \\
\text { BORN 1940-57 }\end{array}$} \\
\hline Pension Wealth ( $\Delta 60-65$ yrs.) & .065 & .016 & .016 & .030 \\
\hline Pension Wealth (level at 60 yrs.) & -.119 & .144 & .141 & .103 \\
\hline Normal Pension Age & - & $.904 \%$ & $.899 * *$ & $.425^{*}$ \\
\hline Earliest Eligibility Age & - & .279 & .274 & .214 \\
\hline Unemployment Rate & - & - & -.010 & $.196 *$ \\
\hline Average Age of Retirement & - & - & - & .743 \\
\hline McKelvey \& Zavoina's $\mathrm{R}^{2}$ & .355 & .414 & .414 & .475 \\
\hline$N$ & 3667 & 3667 & 3667 & 3667 \\
\hline \multicolumn{5}{|l|}{ B) } \\
\hline \multicolumn{5}{|l|}{$\begin{array}{l}\text { ONLY EMPLOYED RESPONDENTS } \\
\text { BORN 1940-57 }\end{array}$} \\
\hline Pension Wealth ( $\Delta 60-65$ yrs.) & .050 & .006 & .010 & .018 \\
\hline Pension Wealth (level at 60 yrs.) & -.163 & .081 & .061 & .083 \\
\hline Normal Pension Age & - & $.758 \cdots$ & $.729 * *$ & .310 \\
\hline Earliest Eligibility Age & - & .269 & .243 & .248 \\
\hline Unemployment Rate & - & - & -.058 & .170 \\
\hline Average Age of Retirement & - & - & - & 671 . \\
\hline McKelvey \& Zavoina's $R^{2}$ & .356 & .405 & .405 & .456 \\
\hline $\mathrm{N}$ & 2012 & 2012 & 2012 & 2012 \\
\hline
\end{tabular}

Source: ESS 32006

$* \mathrm{p}<0.1, * \mathrm{*} p<0.05, \cdots \mathrm{*} * 0.01$

Note: All models include full list of micro level variables (cf. Table 4.3). 
the greater the support for norms of late labour-force exit in a society. To be more specific, one additional year in the normal statutory pension age increases the age of being considered too old to work by almost one year. Among the employed respondents the effect is somewhat weaker. There is no significant association to be found between the earliest age for retirement permitted by a country's pension system and the age of being considered too old to work. ${ }^{44}$

Judging by these findings, age thresholds are the single most influential features of pension systems when it comes to international differences in retirement preferences - more important than discount factors and replacement rates. Therefore, the normative age boundary hypothesis ( $\mathrm{H} 5 \mathrm{~b})$ finds support, adding a caveat to the preference-regulation hypothesis ( $\mathrm{H} 5 \mathrm{a})$.

The explained variance of the regression models is exceptionally high, especially when considering that attitudes are usually much less susceptible to statistical explanation. Although the used pension-wealth variables should be fairly good proxies for the differential incentives provided by public old-agepension systems, they are nevertheless imperfect measures. Moreover, it should be kept in mind that both the variation on these variables and the country sample size are low. Nevertheless, the empirical evidence makes it appear likely that institutionalised age markers indeed exert an impact on age cultures that is independent of monetary incentives.

In the third column of table 4.5, the level of unemployment in a country is added to the regression equation. The revealed work-preferences hypothesis (H6) to be tested implies that higher unemployment among elderly workers translates into lower retirement age norms at the societal level. The model returns the expected negative coefficient. But the effect is small enough not to be significant. This result is independent of the employment status of the respondents, although the coefficient is somewhat bigger among the labourforce population. Apparently, it is not only because unemployment is higher among elderly workers that people change their views on the adequate timing of retirement. People do not seem to adapt their work attitudes simply according to labour market conditions. In short, evidence is not supportive of the revealedwork-preferences hypothesis.

By accounting for the average age of exit from the labour market, the fourth model finally addresses the interdependence between institutions, behavioural regularities, and age norms. The association of the mean retirement age of the foregoing cohort with current views on late retirement is markedly strong. A one

44 Further analyses (not shown) indicate, however, that the youngest age of eligibility is positively related with the age of being considered too young to retire. On this item, the normal statutory pension age, conversely, does not yield a significant association. 
year difference in the average age of retirement corresponds adds eight to nine month to the age at which someone is regarded as too old to work. This lends tentative support to the age-norms-as-conventions hypothesis $(\mathrm{H} 7)$. Holding constant the incentive structure of the pension system and the unemployment rate, the average retirement age of the foregoing cohorts stands in close relation with retirement preferences. Insofar as the other macro variables validly measure institutional characteristics and labour market conditions, it can be speculated that there is some traditionalism in retirement age norms. However, it has already been mentioned above that the model estimates for this variable do not allow for bold causal claims. In any case, the results demonstrate that, at face value, people's opinions regarding the timing of retirement follow a conventional pattern to a considerable degree.

\subsection{Summary}

Age norms of retirement are real. The empirical evidence presented in this chapter leaves little room for doubt that the majority of Western Europeans aged 50 or older hold stylised retirement age norms. Probably as a consequence of the long-lasting trend towards early retirement, older workers' attitudes are today mostly favorable of early exit from work. At the same time, social norms prescribe clear age boundaries for the transition from work to retirement. Very early or very late exit from work is considered inappropriate.

The analyses have furthermore shown a considerable degree of social diversity. For a considerable minority, a conventional work biography ending with retirement at 65 still functions as a binding normative reference. Of course, this minority is not a random sub-group of the elderly population. Instead, the pervasiveness of age norms corresponds to robust empirical regularities.

In essence, retirement preferences are manifestations of class-graded work orientations and gender roles. The central relevance of social class for retirement age norms leads to a rejection of the second-modernity hypothesis, which posits the disappearance of traditional class disparities with regard to life-style preferences. Instead, class remains a crucial driving force of age norms towards work and retirement. Remarkably, this result stands in contrast to previous research, which could not find significant class disparities (Esser 2005). The main divide is between the salariat and the working class. In detail, serviceclass employees and the self-employed consistently favor late retirement. With respect to male retirement norms, they approve of a later exit from work than any other occupational group. Skilled manual workers stand out for displaying an exceptionally weak labour market attachment at the end of working life. The analyses revealed even sharper class disparities in relation to female retirement norms. 
With regard to the comparison of men and women, the empirical analyses point to a complex pattern of gendered retirement attitudes. As expected, early exit from work is generally considered more apposite for women than for men. Moreover, women largely agree with men that lower retirement ages are appropriate for women than for men. When looking at each sex separately and controlling for socioeconomic characteristics, however, women show greater approval for a long working life than men. The fact that this is true for norms directed towards men and women alike runs counter to Hakim's "preference theory." At the same time, however, the great heterogeneity established for women's age norms is well in line with her account. Working women's remarkable approval of norms of late exit is contrasted to inactive women, who exhibit a clear preference for early exit from work. In conclusion, it appears that there is no global gender effect; some women subscribe to traditional gender roles (like most men do), while some are even more work-centered than men. ${ }^{45}$

As for the interaction between class and gender it is noteworthy that female-dominated service jobs mostly show a low level of work attachment. An affinity towards early exit from work is thus by no means limited to the male-dominated blue-collar jobs. Correspondingly, the blue-collar-white-collar distinction is not the most pertinent criterion for explaining heterogeneous retirement preferences. Instead, within both domains, the specificity of skills is fundamental, and class ordering in retirement norms depends on the target gender. For the working population, the affinity towards early retirement is equally pronounced among the intermediate administrative occupations and lower service employees as it is among manual workers. Looking at the entire population aged 50 or older, it can be concluded that - in accordance with class theory - the type of employment relationship is the decisive criterion for the structuring of social norms directed at female retirement.

The interpretation of the observed class-attitudes relationship put forward here assumes an important role for class-dependent work experience. Accordingly, social classes partly differ in their views on the timing of retirement because they work under very diverse conditions, which lead to diverging work satisfaction. However, this social mechanism could not be empirically reconstructed, as model estimations remained inconclusive with respect to job-satisfaction variables. The main reason for this is that objective job quality and the subjective evaluations on behalf of workers do not coincide. Nevertheless, the theoretical relevance of social class goes beyond the issue of working conditions, the central dimensions

45 Note, however, that the analyses compiled in this chapter did not assess Hakim's more controversial claim that preferences would be more important for behaviour than institutional constraints. 
being asset specificity and the nature-of-employment relationship, which clearly exerts a strong impact on norms of late exit from work. In conclusion, the influence of social class on retirement age norms seems to stem from the difference between contract and service employments as well as from skill requirements and the workers' positions in the command structure.

In comparative perspective, the presented evidence reveals huge variation in age cultures across Western European societies. It was confirmed that the cross-national diversity in age norms corresponds with the relative generosity of pension systems towards early retirees. On a closer look, however, it could be shown that this association is mostly due to the age boundaries prescribed by pension regulations. The clustering of responses at quinquennial ages likewise highlights the normative salience of institutionalised retirement ages over and above financial incentives. This incentive-incoherent "customary retirement age effect" even convinced orthodox economists of the existence of social norms for retirement. Astonished, Gruber and Wise (2004b: 13) acknowledge: "Since age sixty-five is the normal retirement age, many employees may think that sixty-five is the age to retire." Analogously, tentative evidence suggests that mere conventionalism may shape people's views on the appropriate age for retirement. The observed behavior in the foregoing generations yields a significant partial correlation with retirement attitudes. As for the level of unemployment, the results are ambiguous. This puts into question the related revealed-preferences hypothesis, according to which high unemployment leads older workers to prefer earlier retirement.

In sum, the country level remains a major leveling field for age norms of retirement. The configuration of national pension systems has emerged from the analyses as the most relevant macro-level determinant of retirement attitudes. Due to their signaling power, the age boundaries of the pension systems function as normative guidelines in retirement planning, over and beyond the inherent monetary incentives. Due to data limitations, the macro-level regressions could only be estimated for male age norms, however, limiting the scope of the findings. Moreover, it was impossible to discern age and cohort effects.

Overall, the (comparative) study of the age norms of retirement has proven a fruitful endeavor. In particular, the class gradient in age norms detected in the present study not only fills a gap in this specific literature but also calls into question conventional wisdom concerning the importance of monetary incentives in retirement behavior. Econometric approaches to retirement nearly exclusively make the assumption of a homogenous preference function. The foregoing analyses have shown, however, that modelling class-graded norms and preferences can help to further disentangle the structure-agency nexus in retirement timing. Employing empirical data on norms and preferences in the analysis of life course transitions emerges as a particularly promising research agenda. 